\title{
Quantifying the amplified bias of PV system simulations due to uncertainties in solar radiation estimates
}

\section{Urraca, Ruben}

2018-12

Urraca , R , Huld , T , Lindfors , A V , Riihelä , A , Javier Martinez-de-Pison , F \& Sanz-Garcia , A 2018, ' Quantifying the amplified bias of PV system simulations due to uncertainties in solar radiation estimates ' , Solar Energy , vol. 176 , pp. 663-677 . https://doi.org/10.1016/j.solener.2

http://hdl.handle.net/10138/299962

https://doi.org/10.1016/j.solener.2018.10.065

cc_by_nc_nd

acceptedVersion

Downloaded from Helda, University of Helsinki institutional repository.

This is an electronic reprint of the original article.

This reprint may differ from the original in pagination and typographic detail.

Please cite the original version. 


\title{
Quantifying the amplified bias of PV system simulations due to uncertainties in solar radiation estimates
}

\author{
Ruben Urraca ${ }^{a}$, Thomas Huld ${ }^{b}$, Anders V. Lindfors ${ }^{c}$, Aku Riiheläc ${ }^{c}$ Francisco Javier \\ Martinez-de-Pison ${ }^{\mathrm{a}}$, Andres Sanz Garcia ${ }^{\mathrm{d}}$ \\ ${ }^{a}$ EDMANS Group, Department of Mechanical Engineering, University of La Rioja, 26004, Logroño, Spain \\ ${ }^{b}$ European Commission, Joint Research Centre, Via Fermi 2749, I-21027 Ispra, Italy \\ ${ }^{c}$ Finnish Meteorological Institute, P.O. Box 503, FI-00101 Helsinki, Finland \\ ${ }^{d}$ CDR Division of Biosciences, University of Helsinki, Viikinkaari, 5 E, P.O. Box 56, 00014, Helsinki, Finland
}

\begin{abstract}
Solar radiation databases used for simulating PV systems are typically selected according to their annual bias in global horizontal irradiance $\left(G_{H}\right)$ because this bias propagates proportionally to plane-of-array irradiance $\left(G_{\mathrm{POA}}\right)$ and module power $\left(P_{\mathrm{DC}}\right)$. However, the bias may get amplified through the simulations due to the impact of deviations in estimated irradiance on parts of the modeling chain depending on irradiance. This study quantifies these effects at 39 European locations by comparing simulations using satellite-based (SARAH) and reanalysis (COSMO-REA6 and ERA5) databases against simulations using station measurements.

SARAH showed a stable bias through the simulations producing the best $P_{\mathrm{DC}}$ predictions in Central and South Europe, whereas the bias of reanalyses got substantially amplified because their deviations vary with atmospheric transmissivity due to an incorrect prediction of clouds. However, SARAH worsened at the northern locations covered by the product $\left(55-65^{\circ} \mathrm{N}\right)$ underestimating both $G_{\mathrm{POA}}$ and $P_{D C}$. On the contrary, ERA5 not only covers latitudes above $65^{\circ}$ but it also obtained the least biased $P_{\mathrm{DC}}$ estimations between $55-65^{\circ} \mathrm{N}$, which supports its use as a complement of satellite-based databases in high latitudes. The most significant amplifications occurred through the transposition model ranging from $\pm 1 \%$ up to $+6 \%$. Their magnitude increased linearly with the inclination angle, and they are related to the incorrect estimation of beam and diffuse irradiance. The bias increased around $+1 \%$ in the PV module model because the PV conversion efficiency depends on irradiance directly, and indirectly via module temperature. The amplification of the bias was similar and occasionally greater than the bias in annual $G_{H}$, so databases with the smallest bias in $G_{H}$ may not always provide the least biased PV simulations.
\end{abstract}

Keywords: satellite-based models; reanalysis; PV system simulation; PV system modeling

\footnotetext{
${ }^{*}$ Corresponding author

Email address: ruben. urraca@unirioja.es (Ruben Urraca)
} 


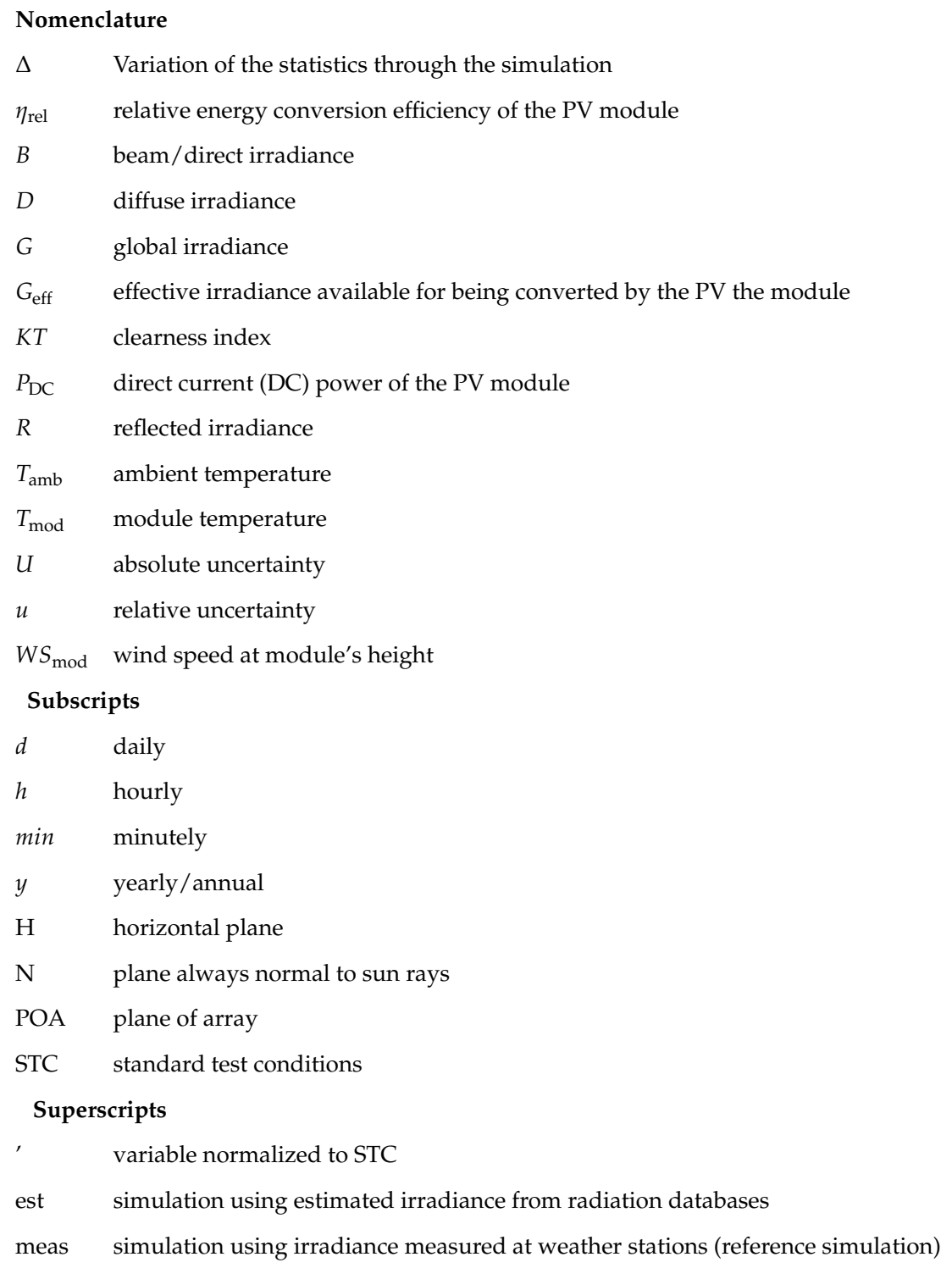

\section{Introduction}

The number of utility-scale and residential PV installations has exponentially increased in the latest years (Jäger-Waldau, 2017). The reasons are the strong cost reduction of PV technology and the appearance of economic incentive policies such as feed-in tariffs (FITs) and net-metering (NET) (Thevenard and Pelland, 2013). A higher penetration of solar PV is held back by the intermittency of the energy generated, which originates from the inherent variability of the solar resource. Part of this variability is caused by stochastic atmospheric processes such as cloud formation (Inman et al., 2013) that complicate PV system modeling and increase the uncertainty of estimations (Ela et al., 2013). The development of accurate simulations is therefore necessary 
to minimize this uncertainty, helping in the deployment of PV systems globally (Thevenard and Pelland, 2013; Hansen and Martin, 2015).

PV simulations are used for yield prediction, i.e., the estimation of the total energy produced by a system during its lifetime. Yield predictions are essential in feasibility studies for selecting the best sites and estimating the financial risk of the investment (Müller et al., 2016; Goss et al., 2012). PV simulations are also part of energy rating, which consists of comparing the real performance of PV modules to that under standard test conditions (STC). Energy rating simulations are evaluated based on the performance ratio (PR) to assess the efficiency of a PV technology under different climatic conditions (Huld and Gracia Amillo, 2015; Huld et al., 2016; Dirnberger et al., 2015). Simulations made for yield prediction consider all specific details of the installation, such as electrical losses and the exact amount of irradiation at the location (including shading, soiling, and snow losses), whereas energy rating simulations are independent of these details. Thus, solar radiation data is more influential for yield predictions, where it is not only the most dominant factor (Cole et al., 2017; Müller et al., 2009) but it also accounts for around $50 \%$ of final uncertainty (Müller et al., 2007; Thevenard and Pelland, 2013; Müller et al., 2017; Richter et al., 2015). Still, uncertainties in irradiance data also affect energy rating simulations because the efficiency of the module under real conditions depends on irradiance.

Ground measurements are the most accurate source of radiation data for PV simulations (Urraca et al., 2018b). However, ground sensors are sparsely distributed and rarely close to the PV system location. The variable commonly measured at weather stations is global horizontal irradiance $\left(G_{H}\right)$ using pyranometers. Few stations record the radiation components: diffuse horizontal irradiance $\left(D_{H}\right)$ is measured with shaded pyranometers whereas beam horizontal irradiance $\left(B_{H}\right)$ is determined from beam normal irradiance $\left(B_{N}\right)$ recorded by pyrheliometers. In-plane irradiance $\left(G_{\mathrm{POA}}\right)$ measurements are even more rare. Therefore, most PV simulations use estimated irradiance (Urraca et al., 2017b), especially those made for feasibility studies requiring several years of data. Satellite-derived databases are the most common choice due to their great progress in the last years (Sengupta et al., 2017; Polo et al., 2016). These databases provide spatially continuous data and are integrated by some of the most popular online PV simulation tools: PVGIS (European Commission JRC, 2018), PVWATTS (NREL, 2018), pvPlanner (GeoModel Solar, 2018), and PV*SOL (Valentin Software, 2018), which use SARAH, NSRDB, SolarGIS, and Meteonorm databases, respectively. Atmospheric reanalyses are another alternative to measurements. They have global coverage and estimate other climatic variables required for PV simulations such as wind speed and temperature. But even with the recent progress made in reanalysis, they generally have coarser spatial resolutions and larger uncertainties than satellite-based models (Urraca et al., 2018b, 2017c).

Solar radiation databases provide $G_{H}, B_{H}$, and $D_{H}$ estimations, so most PV simulations use transposition models to calculate $G_{\mathrm{POA}}$ from horizontal irradiance variables. Radiation databases are generally selected according to their annual bias in $G_{H}$ (Richter et al., 2015), and their suitability is rarely checked in terms of module power $\left(P_{\mathrm{DC}}\right)$ or $G_{\mathrm{POA}}$ due to the lack of measurements. The few validations published included a reduced number of locations (Müller et al., 2009, 2016; Ves, 2013; Roberts et al., 2017; Dobos, 2014; Axaopoulos et al., 2014; Freeman et al., 2014) and seldom compared radiation databases under a common simulation methodology. It would be interesting to clarify whether the databases with the least biased $G_{H}$ estimations are always the ones most suited for PV system modeling by analyzing the propagation of the bias through simulations. Excluding the transposition model, simulation models are basically a series of multiplicative derating factors accounting for different types of losses (Thevenard and Pelland, 2013), so the bias in $G_{H}$ propagates proportionally to $G_{\mathrm{POA}}$ and $P_{\mathrm{DC}}$. However, the bias can change through the simulations because the parameters of some submodels depend on irradiance; this is the case for transposition or power rating models. Cole 
et al. (2017) estimated that the amplification of the bias may be around a $\pm 2 \%$ using satellitebased data, but a more accurate quantification of these effects is needed to improve the selection of radiation databases. These secondary effects are rarely taken into account, but most of them may affect both yield predictions and energy rating simulations.

This paper analyzes the importance of the mentioned secondary effects on the propagation of bias in $G_{H}$ through simulations. For that, we studied separately this propagation in the transposition model (from $G_{H}$ to $G_{\mathrm{POA}}$ ) and the PV module model (from $G_{\mathrm{POA}}$ to $P_{\mathrm{DC}}$ ). The three radiation databases implemented in PVGIS were used: (i) a satellite-based method (SARAH), (ii) a global atmospheric reanalysis (ERA5), and (iii) a regional atmospheric reanalysis (COSMOREA6). The lack of $G_{\mathrm{POA}}$ and $P_{\mathrm{DC}}$ measurements was overcome by comparing simulations made with the radiation databases against a simulation made with station measurements. Simulations were made with crystalline silicon (c-Si) modules at the 39 locations of the weather stations. Deviations from the reference simulation can be attributed to the radiation database because all sub-models and remaining inputs (meteorological data and PV parameters) were kept constant in all simulations.

\section{Solar radiation data on a horizontal plane}

Radiation databases and weather stations were selected by taking into consideration the requirements for simulating PV systems: (i) sub-daily temporal resolution, and (ii) availability of estimations/measurements of both $G_{H}$ and its components $\left(B_{H}\right.$ and $\left.D_{H}\right)$ to avoid using decomposition models (Gueymard and Ruiz-Arias, 2016). The three radiation databases selected are implemented in PVGIS and provide at least two out of the three horizontal irradiance variables (Table 1). An extensive validation of these databases can be found in Urraca et al. (2018a, 2017b, 2018b).

\subsection{Ground measurements}

Ground measurements were retrieved from 39 European weather stations distributed across different latitudes (Fig. 1). The stations belong to the Baseline Surface Radiation Network (BSRN) (BSRN, 2017), the German weather service (Deutscher Wetterdienst, DWD) (DWD, 2016), and the Finnish weather service (Finnish Meteorological Institute, FMI) (FMI, 2016) (Table 1). DWD stations only record $G_{H}$ and $D_{H}$, thus $B_{H}$ was obtained mathematically $\left(B_{H}=\right.$ $\left.G_{H}-D_{H}\right)$. The same procedure was followed at BSRN and FMI stations for homogenization, even though they measure $B_{N}$. Only those years from 2010 to 2015 with more than $7500 \mathrm{~h}$ of simultaneous measurements of $G_{H}$ and $D_{H}$ were used (Table A1). $G_{H}$ and $D_{H}$ were recorded with unshaded and shaded ventilated pyranometers, respectively. The majority of the stations were equipped with secondary standard Kipp\&Zonen pyranometers, except for DWD2928, which had PRM2 (Sonntag) pyranometers (shaded and unshaded) from 2010 to 2013, and DWD-4336 \& DWD-4393, which used a Scanning Pyrheliometer/Pyranometer (SCAPP) (Becker and Behrens, 2012) for measuring $D_{H}$ during 2010.

\subsection{SARAH}

SARAH is a satellite-based dataset produced by the Satellite Application Facility on Climate Monitoring (CM SAF) (CM SAF, 2015) for Europe, Africa, and Asia. SARAH uses images from Meteosat geostationary satellites limiting its spatial coverage to latitudes within $\pm 65^{\circ}$. Surface irradiance is estimated using a semi-empirical method based on the Heliosat algorithm. Reflectivity recorded by visible channels of radiometers on-board Meteosat satellites is used to calculate the effective cloud albedo or cloud index. Then, the cloud index is combined with the 


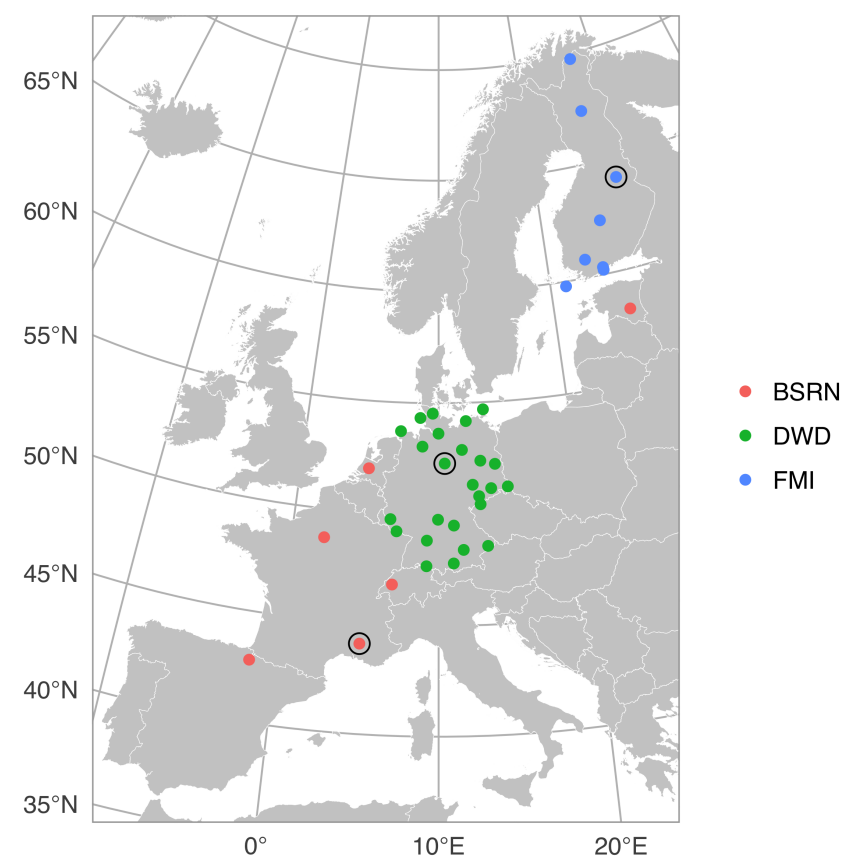

Figure 1: Location of the stations used in this study. The stations surrounded by a black circle were used to analyze the influence of module inclination angle on bias propagation.

estimations of SPECMAGIC clear-sky model to obtain surface irradiance variables. A detailed description of the algorithm is available in Müller et al. (2015c).

Two main versions of SARAH are currently available from CM SAF data server for Europe: SARAH-1 (Müller et al., 2015b) and SARAH-2 (Pfeifroth et al., 2016). Besides, SARAH-East (SARAH-E) (Gracia Amillo et al., 2014) extends SARAH-1 coverage to Asia by using images from Meteosat East satellites. All versions have a spatial resolution of $0.05^{\circ} \times 0.05^{\circ}$ (Table 1). The version used in the present study is a combination of SARAH-1 and SARAH-E implemented by PVGIS (European Commission JRC, 2018). Compared to SARAH-1, this version covers Europe, Africa, and Asia, and it analyzes a single satellite image per hour providing instantaneous hourly estimations of $G_{H}$ and $B_{H}$. Like SARAH-1, it uses monthly averages of water vapor from ERA-interim and monthly climatologies of aerosol optical depth from MACC (MACC Reanalysis, 2015). A detailed validation of this version can be found in Urraca et al. (2017b).

\subsection{ERA5}

ERA5 (ECMWF, 2017) is the newest global atmospheric reanalysis from the European Centre for Medium-range Weather Forecasts (ECMWF). ERA5 will replace ERA-Interim (Dee et al., 2011) as the main ECMWF operational reanalysis by the end of 2019, but up to now, only a preliminary release covering from 2010 to 2017 is available. ERA5 uses a 12-h 4DVar data assimilation system. The main improvements of ERA5 over ERA-Interim are the finer horizontal resolution ( $31 \mathrm{vs.} 79 \mathrm{~km}$ ), the finer vertical resolution (137 vs. 60 levels), the higher temporal frequency for surface irradiance variables ( $1 \mathrm{vs} .3 \mathrm{~h}$ ), the greater amount of data assimilated, and the update of the numeric weather prediction (NWP) model (IFS Cycle 41r2). Surface irradiance variables do not assimilate ground measurements and are obtained with a radiative 
transfer model (RTM) within the NWP model. The two short forecasts are initialized at 6:00 and 18:00 UTC every day. This study uses only the first 12 steps (first $12 \mathrm{~h}$ ) of each short forecast. The variables retrieved are surface solar radiation downwards $(s s r d)$ and total sky direct solar radiation at surface ( $f$ dir $)$. Both provide the accumulated irradiation from the previous to the current step $(1 \mathrm{~h})$. Hourly $G_{H}$ and $B_{H}$ were calculated from ssrd and fdir, respectively, and are thus centered at half-hourly intervals (Table 1 ).

\subsection{COSMO-REA6}

COSMO-REA6 (Bollmeyer et al., 2015) is a regional reanalysis produced by the Hans-ErtelCentre for Weather Research of Deutscher Wetterdienst (HErZ/DWD) for Europe with a resolution of about $6 \mathrm{~km}$. It is generated using the operational NWP model of DWD (COSMO model). COSMO-REA6 implements a continuous nudging scheme, so it can assimilate data at different time intervals. ERA-Interim estimations are used as boundary conditions. The solar radiation scheme uses instantaneous data for clouds and water vapor. Aerosols are modeled with the Tanré climatology, which is known to provide too high aerosol optical thickness for Europe. However, it was kept in COSMO-REA6 because it was the standard input for COSMO NWP model (Frank et al., 2018). COSMO-REA6 provides instantaneous 15-min values for surface irradiance fields. The variables retrieved were instantaneous direct radiation (SWDIFDS_RAD) and instantaneous diffuse radiation (SWDIRS_RAD), which correspond to $D_{H}$ and $B_{H}$, respectively.

Table 1: Summary of the radiation datasets used in this study (2010-2015).

\begin{tabular}{|c|c|c|c|c|c|}
\hline Dataset & Provider & Spatial resolution & Temporal resolution $^{b}$ & Type & Variables \\
\hline \multirow{3}{*}{ Weather stations $(39)^{\mathrm{a}}$} & BSRN (6) & \multirow{3}{*}{ Point value } & $1 \mathrm{~min}$ & avg. & $G_{H}, B_{H}, D_{H}$ \\
\hline & DWD (25) & & $1 \mathrm{~h}(: 30 \mathrm{LST})$ & avg. & $G_{H}, D_{H}$ \\
\hline & FMI (8) & & $1 \mathrm{~h}(: 30 \mathrm{UTC})$ & avg. & $G_{H}, D_{H}$ \\
\hline SARAH PVGIS & CM SAF & $0.05^{\circ} \times 0.05^{\circ}(\sim 5 \mathrm{~km})$ & $1 \mathrm{~h}(: 55 \mathrm{UTC})$ & inst. & $G_{H}, B_{H}$ \\
\hline ERA5 & ECMWF & $0.28^{\circ} \times 0.28^{\circ}(\sim 31 \mathrm{~km})$ & $1 \mathrm{~h}(: 30 \mathrm{UTC})$ & avg. & $G_{H}, B_{H}$ \\
\hline COSMO-REA6 & HErZ/DWD & $0.055^{\circ} \times 0.055^{\circ}(\sim 6.2 \mathrm{~km})$ & $15 \mathrm{~min}$ & inst. & $B_{H}, D_{H}$ \\
\hline
\end{tabular}

${ }^{a}$ Reference dataset. Values in brackets show the number of weather stations from each network.

${ }^{b}$ Values in brackets give the interval midpoint of average values (avg.), and the exact time of instantaneous values (inst.). $\mathrm{LST}=$ local solar time.pl

\section{PV modeling chain}

\subsection{Preprocessing horizontal irradiance data}

Hourly means were calculated at BSRN stations, which were the only ones with sub-hourly temporal resolution (1-min). 15-min averages were calculated if at least 5 samples were available, and hourly means were obtained by averaging 15 -min means if all four 15 -min values were valid. All night values (solar elevation $<0^{\circ}$ ) were set to 0 . The BSRN tests (Long and Dutton, 2002) were used to quality control (QC) hourly ground records. Samples falling out the physically possible and extremely rare limits for $G_{H}$ and $D_{H}$ were considered as not available (NA). A second and more restrictive QC method was applied to all ground measurements. This QC method flags those samples that show a deviation against several radiation databases out of the typical intervals for the time of the year and location (Urraca et al., 2017a). All samples passed the second QC test.

The three radiation databases provide estimations as raster files. In databases with a rather fine spatial resolution (SARAH and COSMO-REA6), the values used were those of the pixel 
containing the station location. In ERA5, the values of the four nearest pixels to the station location were interpolated using inverse distance weighting (IDW). While reanalysis data do not have missing values and their coherence has been already verified, SARAH has missing values at low solar elevation angles (set to -1) and may contain inconsistencies. Thus, SARAH data was preprocessed by setting night values (solar elevation $<0^{\circ}$ ) and missing values at low solar elevation angles $\left(G_{H}=-1, B_{H}=-1\right)$ to 0 for the validation of $G_{H}, B_{H}$ and $D_{H}$. All missing values of SARAH were reconstructed for the simulations using averages of the same hour/day/month in different years. The missing horizontal irradiance variable in each database was calculated based on solar geometry.

\subsection{Transposition model}

Most PV systems have the modules installed at an angle to the horizontal plane to maximize the radiative energy that arrives at the modules. However, both measured and estimated irradiance data are available on the horizontal plane. The transposition model calculates the irradiance on the plane of array (POA) from horizontal irradiance variables by transposing each radiation component separately and subsequently adding them:

$$
G_{\mathrm{POA}}=B_{\mathrm{POA}}+D_{\mathrm{POA}}+R_{\mathrm{POA}},
$$

where $B_{\mathrm{POA}}, D_{\mathrm{POA}}$, and $R_{\mathrm{POA}}$ are the beam, diffuse, and reflected components on the plane of array. $B_{\mathrm{POA}}$ is determined based on solar geometry, and $R_{\mathrm{POA}}$ was calculated from $G_{H}$ assuming an isotropic distribution and a constant ground albedo $\left(\rho_{g}=0.2\right)$. This is the common procedure used in most PV simulations, which typically differ in the type of transposition model for the diffuse component. In this study, we used Muneer's model (Muneer, 1990), which considers the anisotropic diffuse irradiance coming from the horizon and that coming from the circumsolar region. This model compares well with other inclined-plane models (Gracia and Huld, 2013). However, the choice of the inclined-plane model is not critical to the present study because Muneer's model was included in both simulations using radiation databases and those using station measurements. All simulations will predict a decrease in diffuse radiation with increasing inclination (as more and more of the sky will shine on the back of the plane), and an increase in direct radiation from horizontal up to an optimum angle which depends on latitude and the seasonal variation in climate.

\subsection{PV module model}

PV module models can be split into (Fig. 2): (i) the calculation of the effective irradiance $\left(G_{\text {eff }}\right)$, i.e., the portion of $G_{\mathrm{POA}}$ available for being converted into electrical current, and (ii) the calculation of instantaneous $P_{\mathrm{DC}}$ as a function of $G_{\text {eff }}$ and module temperature $\left(T_{\text {mod }}\right)$. $G_{\text {eff }}$ is calculated from $G_{\mathrm{POA}}$ by applying several correction factors accounting for different types of losses:

$$
G_{\text {eff }}=\left(f_{\mathrm{AOI}} \cdot f_{\text {spec }} \cdot f_{\text {snow }} \cdot f_{\text {soiling }} \cdot f_{\text {shading }}\right) \cdot G_{\mathrm{POA}} \approx f_{\mathrm{AOI}} \cdot G_{\mathrm{POA}} .
$$

Spectral losses $\left(f_{\text {spec }}\right)$ were neglected because only SARAH provides spectrally resolved irradiance data. Losses due to the accumulation snow $\left(f_{\text {snow }}\right)$, accumulation of dirt and dust $\left(f_{\text {soiling }}\right)$, and shadows $\left(f_{\text {shading }}\right)$ were also ignored because their impact is independent of the radiation database used. Therefore, the only losses accounted for in this study were the angle of incidence (AOI) effects $\left(f_{\mathrm{AOI}}\right)$. 


\subsubsection{Angle of incidence (AOI) effects}

Some of the light hitting the PV modules will be reflected away from the module surface, and the fraction of light reflected depends on the angle between the module surface and the incoming light. AOI losses were calculated using Martin and Ruiz (2001) model with a value of $a_{r}=0.16$. This model has been included in the Part 2 of the IEC 61853 standard on PV module energy rating (IEC, 2016).

\subsubsection{Model for $P V$ power dependence on temperature and irradiance}

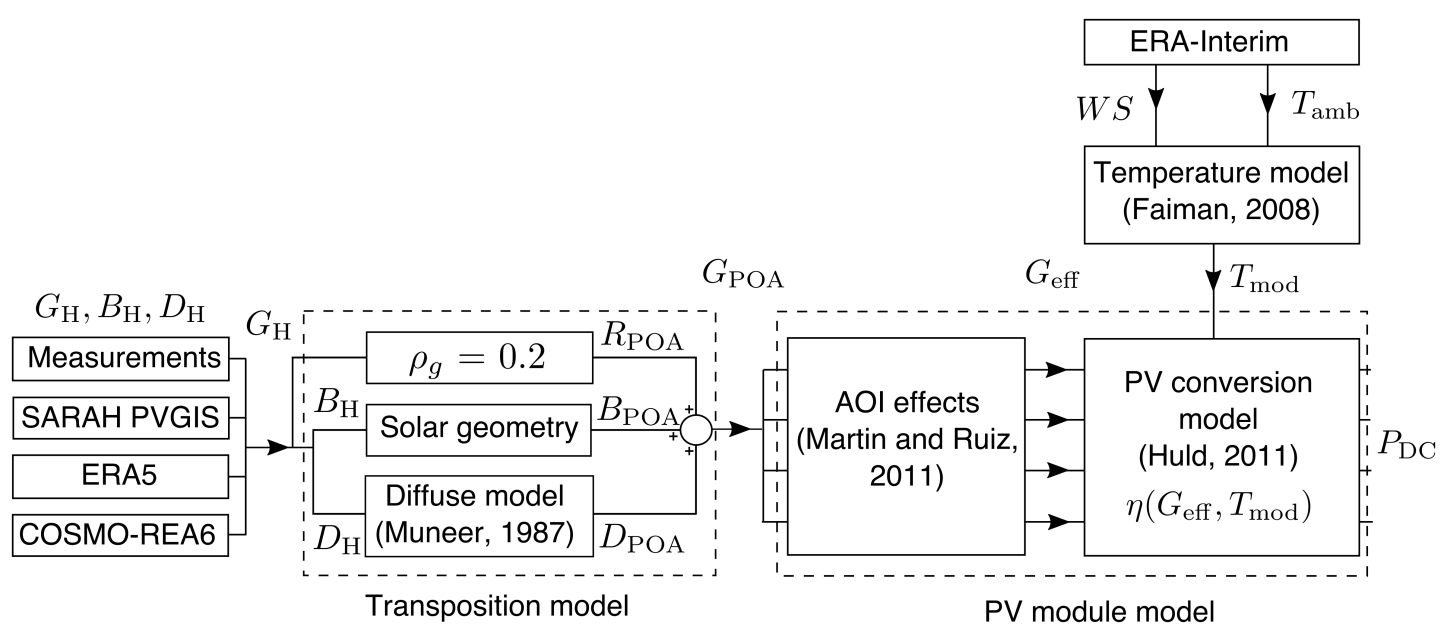

Figure 2: Description of the modeling chain used for the PV system simulations.

The instantaneous power of PV modules at conditions different from those at STC depends on effective in-plane irradiance $\left(G_{\text {eff }}\right)$ and module temperature $\left(T_{\bmod }\right)$. $T_{\bmod }$ was calculated from $G_{\mathrm{POA}}$, ambient temperature $\left(T_{\mathrm{amb}}\right)$, and wind speed at module's height $\left(W S_{\mathrm{mod}}\right)$ with the model proposed by Faiman (2008):

$$
T_{\text {mod }}=T_{\mathrm{amb}}+\frac{G_{\mathrm{POA}}}{u_{0}+u_{1} \cdot W S_{\mathrm{mod}}},
$$

where $u_{0}$ and $u_{1}$ are empirical coefficients. In this case, the values proposed by Koehl et al. (2011) for c-Si modules were used.

The conversion efficiency of PV modules for irradiance and temperature values different from STC was determined with the model suggested by Huld et al. (2011) as

$$
\begin{aligned}
& P_{\mathrm{DC}}^{\prime}\left(G_{\mathrm{eff}}^{\prime}, T_{\mathrm{mod}}^{\prime}\right)=G_{\text {eff }}^{\prime} \cdot \eta_{\mathrm{rel}}\left(G_{\text {eff }}^{\prime}, T_{\mathrm{mod}}^{\prime}\right)=G_{\mathrm{eff}}^{\prime} \cdot\left(1+k_{1} \cdot \ln G_{\text {eff }}^{\prime}+k_{2} \cdot \ln ^{2} G_{\text {eff }}^{\prime}+k_{3} \cdot T_{\text {mod }}^{\prime}+\right. \\
& \left.+k_{4} \cdot T_{\text {mod }}^{\prime} \cdot \ln G_{\text {eff }}^{\prime}+k_{5} \cdot T_{\text {mod }}^{\prime} \cdot \ln ^{2} G_{\text {eff }}^{\prime}+k_{6} \cdot\left(T_{\text {mod }}^{\prime}\right)^{2}\right),
\end{aligned}
$$

where $\eta_{\text {rel }}$ is the relative energy conversion efficiency of the module, and coefficients $k_{1} \cdots k_{6}$ are those reported by Huld et al. (2011) for c-Si modules. All variables in this model are normalized to STC: 


$$
\begin{array}{rll}
P_{\mathrm{DC}}^{\prime}=P_{\mathrm{DC}} / P_{\mathrm{STC}} & \text { with } & P_{\mathrm{STC}}=\text { nominal power } \\
G_{\text {eff }}^{\prime}=G_{\text {eff }} / G_{\mathrm{STC}} & \text { with } & G_{\mathrm{STC}}=1000 \mathrm{~W} / \mathrm{m}^{2} \\
T_{\text {mod }}^{\prime}=T_{\text {mod }}-T_{\mathrm{STC}} & \text { with } & T_{\mathrm{STC}}=25^{\circ} \mathrm{C}
\end{array}
$$

\subsection{Additional meteorological data}

Ambient temperature $\left(T_{\mathrm{amb}}\right)$ and wind speed at module's height $\left(T_{\mathrm{mod}}\right)$ are required to calculate PV module temperature $\left(T_{\mathrm{mod}}\right)$. Both variables were obtained from ERA-Interim (Dee et al., 2011), which estimates $10 \mathrm{~m}$ E-W wind component, $10 \mathrm{~m} \mathrm{~N}-\mathrm{S}$ wind component, and 2 m temperature with a spatial resolution of $0.75^{\circ} \times 0.75^{\circ}(\sim 81 \mathrm{~km})$ and a temporal frequency of $3 \mathrm{~h}$. $T_{\mathrm{amb}}$ was assumed to be equal to $2 \mathrm{~m}$ temperature. $W S_{\text {mod }}$ was obtained by adding in quadrature the two wind components and using the power law (Chen et al., 1998) to estimate WS variation with height:

$$
W S_{\text {mod }}=W S_{10 \mathrm{~m}} \cdot\left(z_{\bmod } / 10\right)^{\alpha},
$$

where $z_{\text {mod }}$ is the module's height and $\alpha$ is the power law index, an empirically derived coefficient that depends on terrain roughness and atmospheric stability. In this case, $z_{\bmod }$ and $\alpha$ were assumed to be $2 \mathrm{~m}$ and 0.2 , respectively. Linear interpolation was used to obtain hourly $W S_{\text {mod }}$ and $T_{\mathrm{amb}}$ from the 3-h ERA-Interim estimates. Besides, $T_{\mathrm{amb}}$ estimates were downscaled using the procedure described in Huld and Pinedo (2015) to account for the local terrain variations.

\section{Validation}

\subsection{Evaluation of bias propagation through the simulation}

The PV simulations were made at the locations of the 39 weather stations from 2010 to 2015, using c-Si modules with a nominal power of $1 \mathrm{~kW}\left(P_{\mathrm{STC}}=1 \mathrm{~kW}\right)$ and an inclination angle of $45^{\circ}$. Results were independent of $P_{\text {STC }}$ because the analysis was based on relative metrics. The deviations between simulations using estimated irradiance (subscript 'est') and the simulation using station measurements (subscript 'meas', reference simulation) were calculated for each radiation database (Eq. 9). The presence of uncertainty in the reference values was emphasized by using the term "deviation" instead of "error" (Gueymard, 2014), and it is further discussed in Appendix B. Even though the simulations were made with hourly values, hourly deviations could not be calculated because hourly intervals were defined differently in radiation databases and weather stations (Table 1). Thus, deviations were calculated with the daily irradiance means as

$$
\text { deviation }_{d}(X)=X_{d}^{\text {est }}-X_{d}^{\text {meas }} \quad X \in\left(G_{H}, B_{H}, D_{H}, G_{\mathrm{POA}}, P_{\mathrm{DC}}\right),
$$

where the daily means $\left(X_{d}\right)$ were obtained by averaging hourly values if at least 21 values per day were available $(\max N A s=3)$. This procedure gives the "true error" only for horizontal irradiance variables $\left(G_{H}, B_{H}, D_{H}\right)$ because these are the only ones for which $X^{\text {meas }}$ is actually measured data. In $G_{\mathrm{POA}}$ and $P_{\mathrm{DC}}, X^{\text {meas }}$ is the prediction obtained with the simulation based on ground measurements, so the deviations show the difference between predictions using estimated irradiance and that using station measurements.

The annual relative bias (bias $y[\%]$ ) of daily deviations was calculated to analyze the suitability of each solar radiation database for PV simulations because the feasibility of PV systems is commonly evaluated based on annual yield predictions (Müller et al., 2017). 


$$
\operatorname{bias}_{y}(X)[\%]=\frac{\frac{1}{N_{d}} \sum_{n=1}^{N_{d}}\left(X_{d}^{\text {est }}-X_{d}^{\text {meas }}\right)}{\frac{1}{N_{d}} \sum_{n=1}^{N_{d}} X_{d}^{\text {meas }}} \cdot 100 \quad X \in\left(G_{H}, B_{H}, D_{H}, G_{\mathrm{POA}}, P_{\mathrm{DC}}\right),
$$

where $N_{d}$ is the number of days per year with available values for both the simulation based on estimations and the reference simulation. The annual bias was calculated only if $N_{d}>312$ days $(\approx 7500 \mathrm{~h}$ ) to guarantee that the bias was representative of irradiance conditions throughout the whole year.

The influence of the intra-annual distribution of deviations on the propagation of the bias was evaluated with the scatter plots of daily relative deviations (deviation ${ }_{d}[\%]$ ) against clearness index $(K T)$. Relative deviations were obtained by dividing absolute daily deviations by the annual mean of $X$ in the reference simulation instead of by its daily value:

$$
\text { deviation }_{d}(X)[\%]=\frac{X_{d}^{\text {est }}-X_{d}^{\text {meas }}}{\frac{1}{N_{d}} \sum_{n=1}^{N_{d}} X_{d}^{\text {meas }}} \cdot 100 \quad X \in\left(G_{H}, B_{H}, D_{H}, G_{\mathrm{POA}}, P_{\mathrm{DC}}\right) .
$$

Thereby, deviation ${ }_{d}[\%]$ shows the actual contribution of each daily deviation to the bias $_{y}[\%]$ eliminating the dependence of relative daily metrics on the seasonal variation of the solar resource. The $K T$, which is a common indicator of the atmospheric transmissivity, was calculated as

$$
K T=\frac{G_{H}}{E_{H}},
$$

where $E_{H}$ is the extraterrestrial irradiance received on a horizontal plane.

The use of relative metrics enabled the comparison of the values obtained in the different steps of the simulation chain. Therefore, the propagation of the bias in the transposition model (from $G_{H}$ to $G_{\mathrm{POA}}$ ) and the PV module model (from $G_{\mathrm{POA}}$ to $P_{\mathrm{DC}}$ ) were obtained as

$$
\begin{aligned}
& \Delta \operatorname{bias}_{y}(\text { trans.model })=\operatorname{bias}_{y}\left(G_{\mathrm{POA}}\right)-\operatorname{bias}_{y}\left(G_{H}\right) \\
& \Delta \text { deviation }_{d}\left(\text { trans.model }=\text { deviation }_{d}\left(G_{\mathrm{POA}}\right)-\text { deviation }_{d}\left(G_{H}\right)\right. \\
& \Delta \operatorname{bias}_{y}(\mathrm{PVmod} . \mathrm{model})=\operatorname{bias}_{y}\left(P_{\mathrm{DC}}\right)-\operatorname{bias}_{y}\left(\mathrm{G}_{\mathrm{POA}}\right) \\
& \Delta \text { deviation }_{d}(\mathrm{PVmod} \cdot \mathrm{model})=\text { deviation }_{d}\left(P_{\mathrm{DC}}\right)-\text { deviation }_{d}\left(G_{\mathrm{POA}}\right) .
\end{aligned}
$$

Note that in the present study, both positive and negative changes of the bias through the simulation have negative connotations regardless of whether the absolute value of the bias decreases.

\subsection{Influence of the module inclination angle on bias propagation}

The influence of the module inclination angle on bias propagation was analyzed by varying the inclination angle from $0^{\circ}$ to $65^{\circ}$ in $5^{\circ}$ intervals. These simulations were made only at three locations (Fig. 1): (i) BSRN-CAR (Carpentras), a low-latitude station $\left(44.08^{\circ}\right)$ situated in a sunny region with a high frequency of clear conditions, (ii) DWD-662 (Branuschweig), a mid-latitude station $\left(52.29^{\circ}\right)$ located in a cloudy region, and (iii) FMI-4714 (Sotkamo), a high-latitude station $\left(64.11^{\circ}\right)$ located in a region with seasonal snow and low solar elevations during winter. 


\section{Results and discussion}

\subsection{Propagation of the bias through PV simulations}

The annual bias in $G_{H}$ and $G_{P O A}$ was analyzed separately below and above $55^{\circ} \mathrm{N}$ (Fig. 3) because the performance of radiation databases changes in high latitudes due to seasonal snow, low solar elevation angles, and low satellite viewing angles. SARAH obtained the smallest annual bias in $G_{H}$ below $55^{\circ} \mathrm{N}$ (bias $y=-0.06 \%$ ). It showed a decreasing bias with increasing latitude, obtaining negative biases in Northern Germany and particularly in the Nordic countries bias $\left._{y}=-4.87 \%\right)$. SARAH-1 and SARAH-E underestimate near the edge of satellite images due to an overestimation of cloud thickness because satellites view clouds at very shallow angles (Müller et al., 2015a; Gracia Amillo et al., 2014). This issue has been addressed in SARAH-2 with an empirical correction of the cloud index as a function of the satellite zenith angle, but it has not been implemented in SARAH PVGIS yet. The negative bias was stronger in winter (Fig. 6), which may be related to an over-prediction of clouds over snow-covered surfaces (Müller et al., 2015a). COSMO-REA6 showed the largest bias by underestimating $G_{H}$ across all latitudes $(-4.99 \%$ and $-5.98 \%)$. This is a well-known problem of COSMO-REA6 caused by the use of an aerosol climatology that introduces a too high aerosol content (Frank et al., 2018). The most homogeneous distribution of the annual bias in $G_{H}$ over Europe (Fig. 3a) corresponded to ERA5, with a moderate overestimation of $G_{H}$ below $55^{\circ} \mathrm{N}$ (bias b $_{y}=+1.67 \%$ ) and a low underestimation in high latitudes $\left(\right.$ bias $_{y}=-1.43 \%$ ). Thus, ERA5 was the database with the smallest bias above $55^{\circ} \mathrm{N}$, while the smallest bias below $55^{\circ} \mathrm{N}$ corresponded to SARAH.

Annual biases in $P_{\mathrm{DC}}$ differed from those obtained in $G_{H}$ at some locations. SARAH obtained the most stable bias through simulations (Fig. $3 b$ ), with $\Delta b i a s_{y}$ within $\pm 1.8 \%$ in the transposition model and a negligible $\Delta$ bias $_{y}$ within $\pm 0.1 \%$ in the PV module model. In the transposition model, the bias got more positive below $55^{\circ} \mathrm{N}\left(\Delta\right.$ bias $\left._{y}=+1.8 \%\right)$ and more negative in the Nordic countries $\left(\Delta b i a s_{y}=-1.46 \%\right)$. COSMO-REA6 presented a similar propagation pattern to that of SARAH in the transposition model, but COSMO-REA6 obtained a non-negligible $\Delta$ bias $_{y}$ of $+0.92 \%$ in the PV module model. The increase in bias below $55^{\circ} \mathrm{N}$ canceled out the negative bias in $G_{H}$ leading to a moderate bias in $P_{\mathrm{DC}}$, whereas the decrease of bias in high latitudes accentuated the negative bias in $P_{\mathrm{DC}}$. The largest bias amplification was obtained by ERA5 below $55^{\circ} \mathrm{N}$, with $\Delta$ bias $_{y}=+6.09 \%$ in the transposition model and $\Delta$ bias $_{y}=+1.52 \%$ in the PV module model. This led to a large bias in $P_{\mathrm{DC}}(+9.29 \%)$ despite the moderate bias in $G_{H}(+1.67 \%)$ obtained by ERA5. ERA5 performance sharply changed in Northern Europe becoming the best radiation database in terms of $G_{H}$ and the one showing the most stable bias through simulations $\left(\operatorname{bias}_{y}=+1.44 \%\right)$. Therefore, ERA5 was the best performing database in high latitudes with an annual bias in $P_{\mathrm{DC}}$ of $+0.01 \%$, whereas SARAH remained as the database with the smallest annual bias in $P_{\mathrm{DC}}$ below $55^{\circ} \mathrm{N}(+1.64 \%)$.

The interpretation of the results is constrained by the uncertainty in the reference simulation (see Appendix B). Annual biases of horizontal irradiance variables were greater than the uncertainty of the reference simulation at the majority of stations (Table 2). The exceptions were found in SARAH below $55^{\circ} \mathrm{N}$ and ERA5 above $55^{\circ} \mathrm{N}$, where around half of the stations were within the uncertainty limits because of the low deviations of both databases in those regions. For $G_{\mathrm{POA}}$ and $P_{\mathrm{DC}}$, the number of stations within the uncertainty limits increased because both variables were not measured but estimated by feeding horizontal irradiance measurements to the simulation model. However, values shown in Table 2 are the worst-case scenario. The true number of biases greater than the uncertainty in the reference simulation should be considerably larger because test and reference simulations used the same transposition and PV module model. Thus, systematic deviations introduced by these models cancel out. Nonetheless, $G_{\mathrm{POA}}$ and $P_{\mathrm{DC}}$ deviations were still significant for ERA 5 below $55^{\circ} \mathrm{N}$ and COSMO-REA6 above $55^{\circ} \mathrm{N}$ 

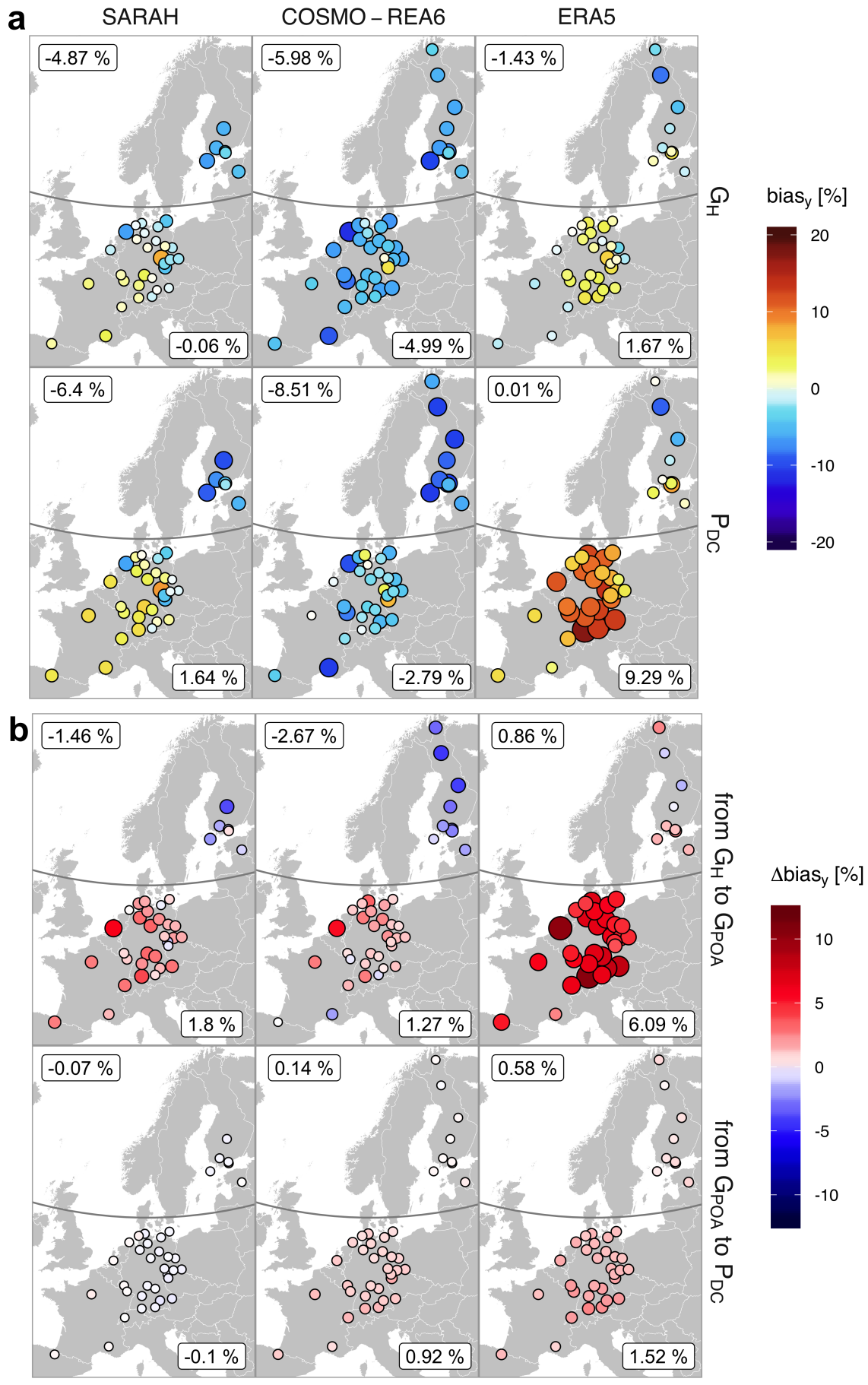

Figure 3: (a) Distribution of the annual bias in $G_{H}$ and $P_{\mathrm{DC}}$. (b) Distribution of the propagation of the annual bias in the transposition model (from $G_{H}$ to $G_{\mathrm{POA}}$ ) and the PV module model (from $G_{\mathrm{POA}}$ to $P_{\mathrm{DC}}$ ). Values in the box represent the mean bias at locations over and under $55^{\circ} \mathrm{N}$. 
even in this worst-case scenario. Concerning the uncertainties at DWD and FMI stations, we did not observe any significant difference between the results obtained at BSRN stations and those obtained at FMI or DWD. This suggests that the variations of uncertainty between stations were negligible and did not interfere significantly in the interpretation of the results.

Table 2: Percentage of annual biases greater than the annual uncertainty of the reference simulation.

\begin{tabular}{llccccc} 
& Database & $G_{H}$ & $B_{H}$ & $D_{H}$ & $G_{P O A}{ }^{*}$ & $P_{D C}{ }^{*}$ \\
\hline \multirow{3}{*}{ Latitude $<55^{\circ}$} & SARAH & 57 & 42 & 62 & 30 & 24 \\
& COSMO-REA6 & 91 & 75 & 74 & 34 & 20 \\
& ERA5 & 60 & 96 & 100 & 73 & 77 \\
\hline \multirow{3}{*}{ Latitude $>55^{\circ}$} & SARAH & 62 & 91 & 81 & 38 & 34 \\
& COSMO-REA6 & 82 & 95 & 75 & 70 & 52 \\
& ERA5 & 30 & 34 & 64 & 11 & 11 \\
\hline
\end{tabular}

* In the reference simulation, $G_{P O A}$ and $P_{D C}$ are estimated using the irradiance measurements as inputs to the PV simulation model.

These results evidence that, despite the bias in $G_{H}$ is the main driver of the bias in $P_{\mathrm{DC}}$, the bias significantly changes through the simulations. Deviations observed were exclusively due to the source of radiation data, so changes in the bias through the simulations were caused by secondary effects of uncertainties in estimated irradiance on the modeling chain. The magnitude and sign of these changes varied between databases and locations, and in some cases, they were even greater than the magnitude of the annual bias in $G_{H}$. Therefore, the best radiation database in terms of $G_{H}$ does not assure the least biased PV estimations, so the bias in $G_{H}$ alone may not be an adequate criterion to select radiation databases. For example, the annual bias in $G_{H}$ of ERA5 was smaller than that of COSMO-REA6 (+1.67 vs. $\left.-4.99 \%\right)$, but the amplification of ERA5 bias through the simulations made that its annual bias in $P_{\mathrm{DC}}$ was greater than that of COSMO-REA6 (+9.29 vs. $-2.79 \%$ ). In the following sections, we analyze the root of these variations by studying independently the bias propagation through the transposition model (Subsection 5.2) and the PV module model (Subsection 5.3).

\subsection{Propagation of the bias through the transposition model}

The propagation of the bias in the transposition model was studied based on the distribution of daily deviations against $K T$ (Fig. 4), the deviations of $B_{H}$ and $D_{H}$ (Fig. 5), and the intra-annual distribution of these deviations (Fig. 6). The role of radiation components in the transposition model is essential because they are transposed separately (Fig. 2), and the contribution of each component varies with the inclination angle: the contribution of beam irradiance increases up to the optimum inclination angle whereas the contribution of diffuse irradiance decreases (Subsection 3.2). Therefore, an unbalanced estimation of radiation components $\operatorname{bias}_{y}\left(G_{H}\right) \neq \operatorname{bias}_{y}\left(D_{H}\right) \neq \operatorname{bias}_{y}\left(B_{H}\right)$ ) will be accentuated through the transposition model leading to large errors in $G_{\mathrm{POA}}$. The bias in $G_{\mathrm{POA}}$ will get more negative when $B_{H}$ is underestimated $\operatorname{bias}_{y}\left(B_{H}\right)<\operatorname{bias}_{y}\left(G_{H}\right)$ ) and more positive when $B_{H}$ is overestimated $\left.\operatorname{~bias~}_{y}\left(B_{H}\right)>\operatorname{bias}_{y}\left(G_{H}\right)\right)$ because beam irradiance plays a dominant role close to the optimum inclination angle. Regarding reflected irradiance, the relative bias in $R_{P O A}$ will be proportional to that in $G_{\mathrm{H}}$ because $R_{\mathrm{POA}}$ was calculated from $G_{\mathrm{H}}$ assuming a constant ground albedo. However, the contribution of $R_{\mathrm{POA}}$ to $G_{\mathrm{POA}}$ is substantially smaller than that of beam or diffuse irradiance, so $R_{\mathrm{POA}}$ is not analyzed in this section.

The bias of SARAH slightly changed through the transposition model below $55^{\circ} \mathrm{N}\left(\Delta b i a s_{y}\right.$ $=+1.8 \%$ ) because of a balanced estimation of the radiation components $\left(\right.$ bias $_{y}\left(B_{H}\right)=-0.91 \%$, 


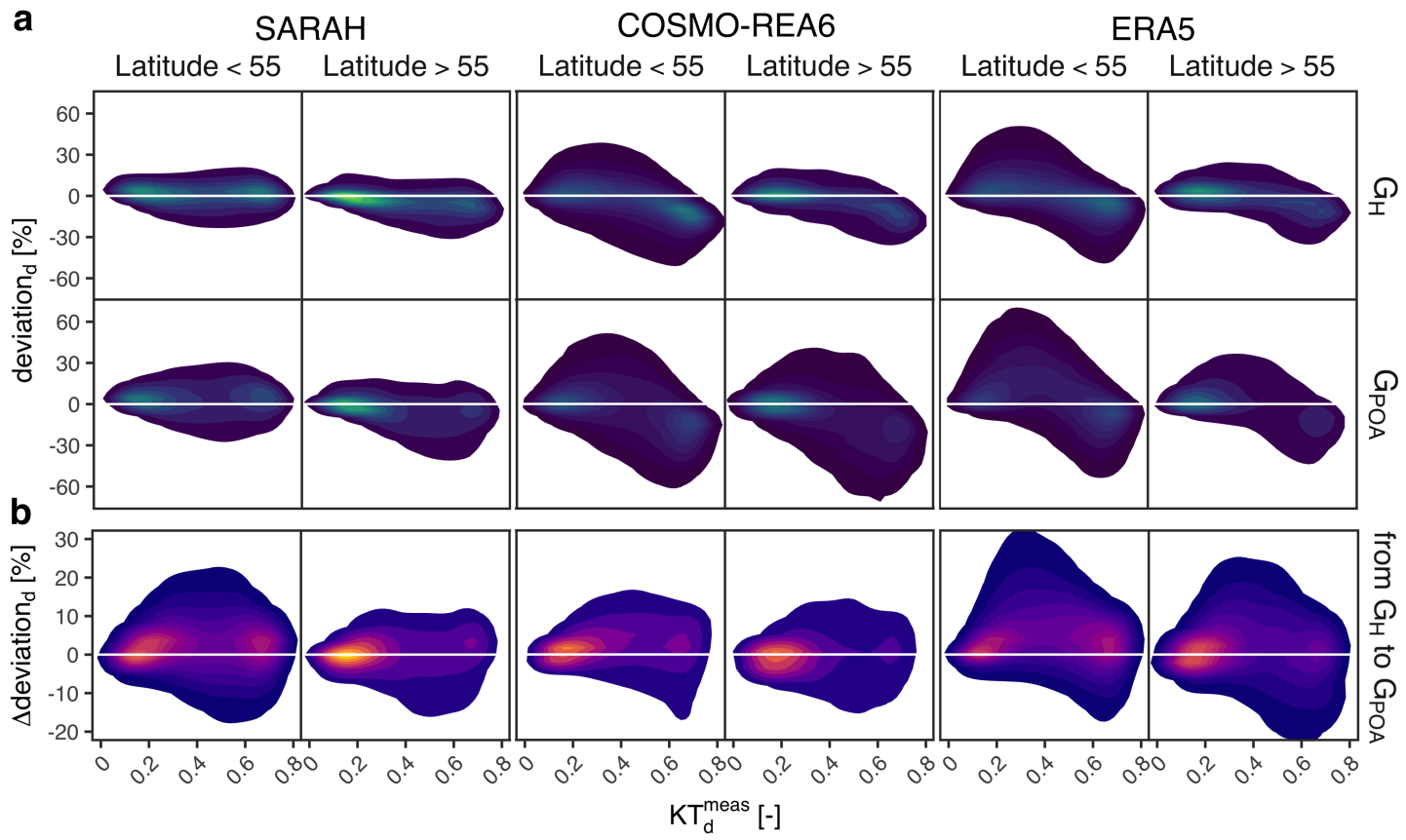

Figure 4: (a) 2D density plot of daily deviations in $G_{H}$ and $G_{\mathrm{POA}}$ between radiation databases and station measurements. (b) 2D density plot of the change of daily deviations through the transposition model.

$\operatorname{bias}_{y}\left(D_{H}\right)=+0.97 \%$ ) (Fig. 5). The increase of the bias may be partly explained by the presence of missing values at low solar elevations. These values were set to 0 for the validation of horizontal irradiance while they were reconstructed for PV simulations, introducing a small negative bias in $G_{H}, B_{H}$ and $D_{H}$ when compared to $G_{\mathrm{POA}}$ and $P_{\mathrm{DC}}$. The $\Delta$ bias $_{y}$ was more negative with an increasing latitude (Fig. 3b) due to the greater underestimation of $B_{H}$ (Fig. 5a) that canceled out the overestimation caused by missing values. Therefore, $\Delta b i a s_{y}$ was $-1.46 \%$ above $55^{\circ} \mathrm{N}$ driven by the strong imbalance between the radiation components $\left(\operatorname{bias}_{y}\left(B_{H}\right)=-14.91 \%, \operatorname{bias}_{y}\left(D_{H}\right)=\right.$ $+8.18 \%$ ). The underestimation of SARAH in $G_{H}$ and $G_{\mathrm{POA}}$ was strong under clear conditions in winter and spring (Fig. 6), which may be related to the known limitations of SARAH on detecting snow (Müller et al., 2015a). SARAH detects clouds solely with images from the visible channels of radiometers on-board geostationary satellites. These images are not sufficient to robustly distinguish between snow and clouds because both have high reflectivity, leading to an over-prediction of clouds over snow-covered surfaces. In high latitudes, the imbalance between $B_{H}$ and $D_{H}$ (positive bias in $D_{H}$, negative bias in $B_{H}$ ) was also large in summer under clear conditions (Fig. 6), which may be related to other issues such as aerosols or the overestimation of cloud thickness at shallow satellite viewing angles.

The bias of COSMO-REA6 got more positive through the transposition model below $55^{\circ} \mathrm{N}$ $\left(\Delta\right.$ bias $\left._{y}=+1.27 \%\right)$ and more negative in high latitudes $\left(\Delta\right.$ bias $\left._{y}=-2.67 \%\right)$. Compared to SARAH, COSMO-REA6 presented an uneven distribution of the deviations (Fig. 4), underestimating under clear sky and overestimating under cloudy conditions as reported by the own HErZ/DWD (Frank et al., 2018, 2017). Negative deviations under clear sky are caused by the well-known overestimation of Tanré aerosol climatology, which leads to the underestimation of $B_{H}, G_{H}$ and $B_{H}$ in mid and low latitudes. These deviations are more visible during the central months of the year (Fig. 6). Conversely, positive deviations for $K T s<0.5$ are caused by the prediction of 


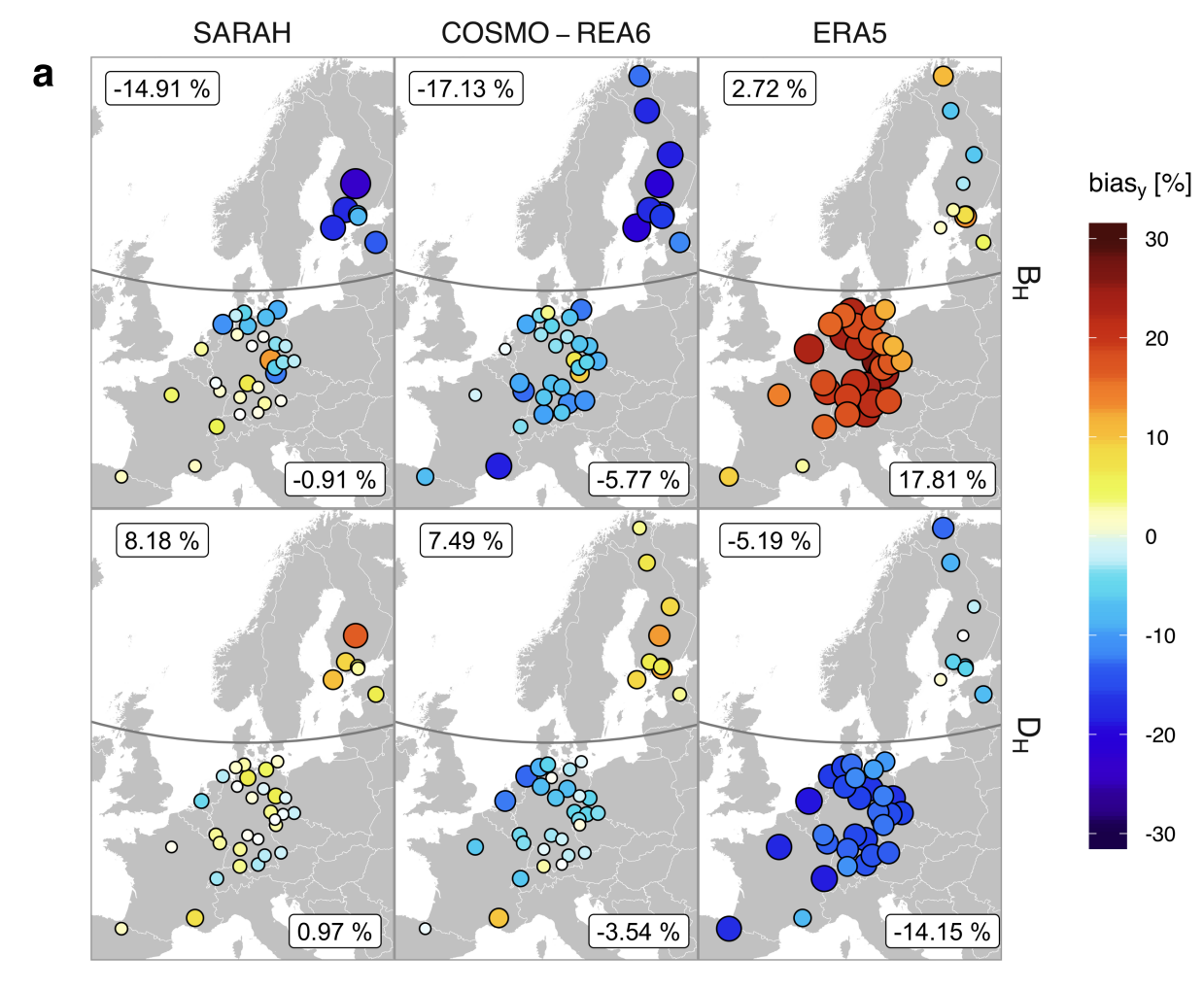

b

SARAH

COSMO-REA6

ERA5

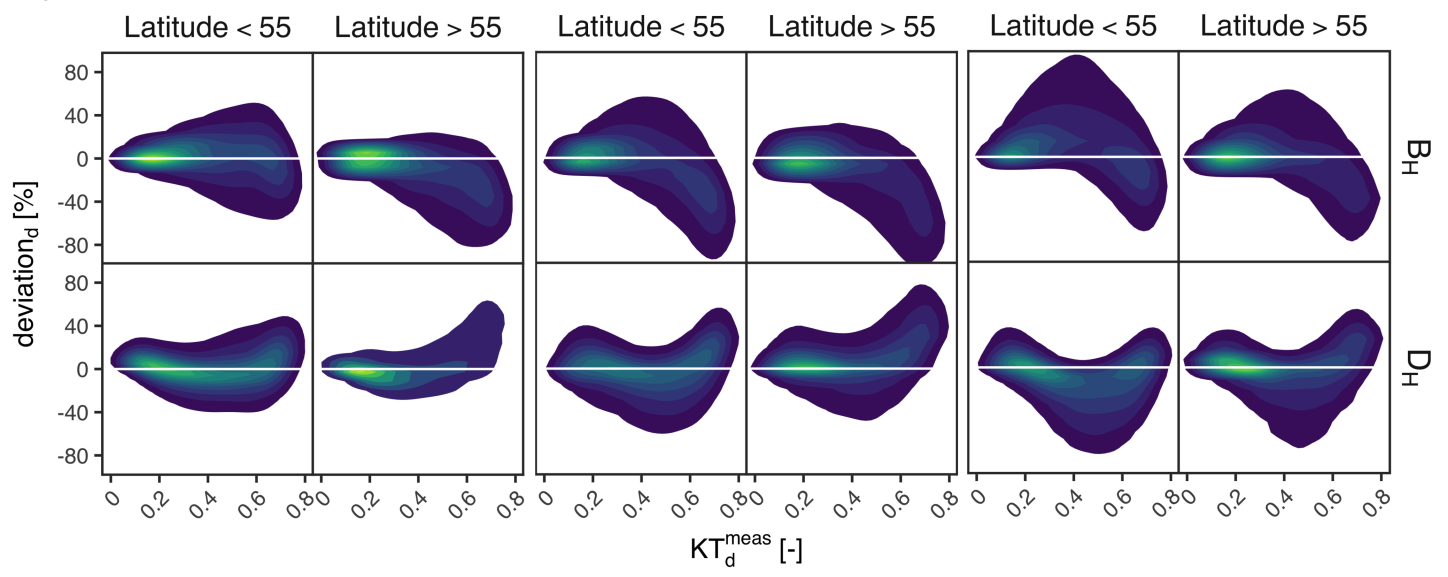

Figure 5: (a) Distribution of the annual bias in $B_{H}$ and $D_{H}$. (b) 2D density plot of daily deviations in $B_{H}$ and $D_{H}$ between radiation databases and station measurements against the daily clearness index $\left(K T_{d}^{\text {meas }}\right)$. Values in the box represent the average bias at locations over and under $55^{\circ} \mathrm{N}$.

optically too thin or too few clouds (Frank et al., 2018) and lead to the overestimation of $B_{H}$ and the underestimation of $D_{H}$ (Fig. 5). Below $55^{\circ} \mathrm{N}$, both effects virtually balance each other (Fig. 5b). The bias of COSMO-REA6 slightly got more positive due to the overestimation of $B_{H}$ under cloudy conditions and the predominantly high-cloudiness at the sites evaluated below 


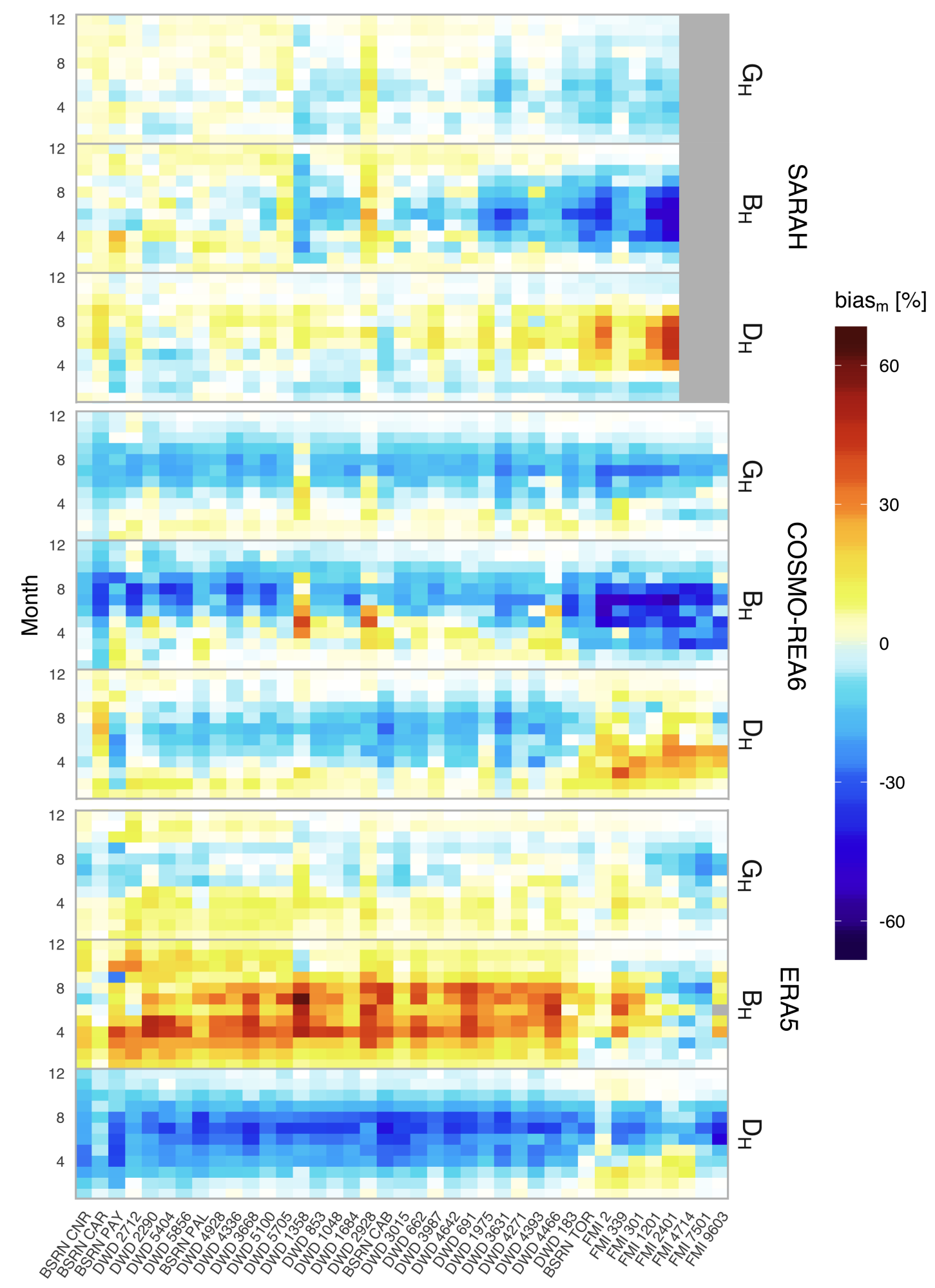

Figure 6: Heatmap of monthly-aggregated relative bias $\left(\right.$ bias $\left._{m}\right)$ in $G_{H}, D_{H}$ and $B_{H}$. Stations are sorted from left to right by increasing latitude. 
$55^{\circ} \mathrm{N}$. Above $55^{\circ} \mathrm{N}$, the overestimation of $B_{H}$ under cloudy conditions was somehow mitigated. Therefore, the underestimation of $B_{H}$ under clear conditions prevailed leading to a negative $\Delta b i a s_{y}$ through the transposition model of $-2.67 \%$. The bias became more negative as well at southern locations because the underestimation of $B_{H}$ caused by the excess of aerosol content was accentuated by the high frequency of clear conditions (Fig. 5). Overall, both SARAH and COSMO-REA6 presented a similar propagation pattern in the transposition model, with a moderate positive $\Delta b i a s_{y}$ below $55^{\circ} \mathrm{N}$ and a large negative $\Delta b i a s_{y}$ in high latitudes, though the causes of these changes differed in each database.

ERA5 showed a significantly positive $\Delta$ bias $_{y}$ of $+6.09 \%$ through the transposition model below $55^{\circ} \mathrm{N}$, which may be explained by the great imbalance between beam and diffuse irradiance $\left(\right.$ bias $_{y}\left(B_{H}\right)=+17.81 \%$, bias $\left._{y}\left(D_{H}\right)=-14.15 \%\right)$ (Fig. 5). Similarly to COSMO-REA6, ERA5 overestimated and underestimated $G_{H}$ for low and high $K T$ s, respectively. However, the overestimation of $G_{H}$ under cloudy conditions was substantially more accentuated in ERA5 than in COSMO-REA6 (Fig. 4a). This is related to different failures in the prediction of clouds such as false prediction of clear-sky situations, underestimation of the cloud fraction, optically too thin clouds, or incorrect cloud properties (cloud phase or liquid/ice water content), among others (Urraca et al., 2018a). These defects led to an overestimated $B_{H}$ for $K T s<0.5$ (Fig. $4 \mathrm{~b}$ ), and thus, to an overestimated $G_{\mathrm{POA}}$. The performance of ERA5 completely changed in the Nordic countries because of a reduced overestimation of $B_{H}$ under cloudy conditions, leading to a better balanced estimation of radiation components (Fig. 5). The overestimation of $B_{H}$ for KTs $<$ 0.6 canceled the underestimation of $B_{H}$ for $K T s>0.6$, producing a moderate $\Delta b i a s_{y}=+0.86 \%$. Thus, ERA5 presented the smallest $\Delta$ bias $_{y}$ through the transposition model above $55^{\circ} \mathrm{N}$, which contrasts with its poor performance below $55^{\circ} \mathrm{N}$ where it obtained the largest $\Delta$ bias $_{y}$ overall.

The bias of reanalysis databases was substantially amplified through the transposition model due to the uneven performance of these models with the atmospheric transmissivity. Reanalyses underestimate and overestimate $G_{H}$ under clear and cloudy conditions, respectively. This pattern may be related to random errors in cloud placement because even the best solar radiation models will show clouds under clear conditions and vice versa. Typically, these random errors do not affect the annual bias because they cancel out, but they still lead to an incorrect estimation of beam and diffuse irradiance amplifying the bias through the simulations. Besides, in this case, random errors were not fully averaged out. COSMO-REA6 showed a negative bias due to the overestimation of aerosols under clear skies, whereas ERA5 showed a positive bias due to the strong underestimation of clouds under cloudy conditions. Conversely, the performance of SARAH was uniform under different atmospheric conditions, especially below $55^{\circ} \mathrm{N}$. We conclude that the principal limitation of reanalyses when simulating PV systems is the high intra-annual variability of their bias caused by cloud-related errors.

\subsection{Propagation of the bias through the PV module model}

The PV module model comprises the estimation of $G_{\text {eff }}$ from $G_{\mathrm{POA}}$ and the estimation of $\eta_{\mathrm{rel}}$ for temperature and irradiance values different from those under STC (Fig. 2). In this study, the estimation of $G_{\text {eff }}$ only accounted for AOI losses, which depend on solar geometry and are virtually independent of the radiation database. Therefore, variations of the bias through the PV module model primarily occurred in the estimation of $\eta_{\text {rel }}$, and they were caused by second-order effects of irradiance errors on the model that calculates $\eta_{\text {rel }}$. These effects are twofold because $\eta_{\text {rel }}$ depends on irradiance directly (Fig. 7a) and indirectly via module temperature (Fig. 7b). Irradiance and temperature were the predominant factors at low and high irradiances, respectively. Therefore, $\eta_{\text {rel }}$ increases with irradiance until a value of around $400 \mathrm{~W} / \mathrm{m}^{2}$, after which it decreases due to the heating of the cell (Fig. 7c) (Huld et al., 2008). 


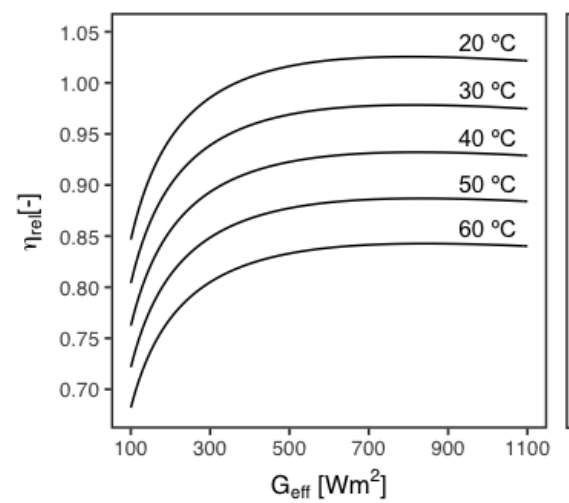

b

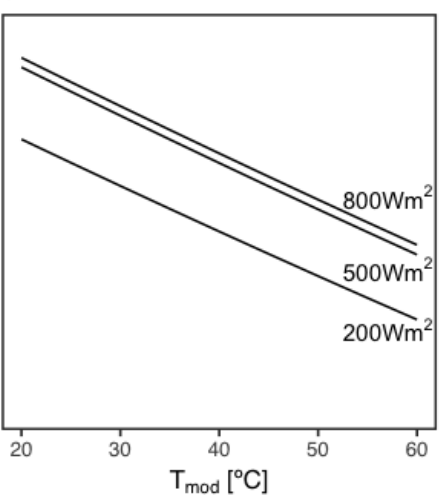

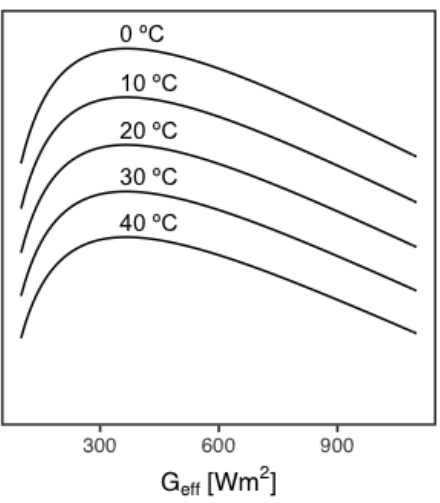

Figure 7: Relative energy conversion efficiency $\left(\eta_{\text {rel }}\right)$ of c-Si modules (a) as a function of irradiance for constant module temperature, (b) as a function of module temperature for constant irradiance, (c) and as a function of irradiance for constant ambient temperature.

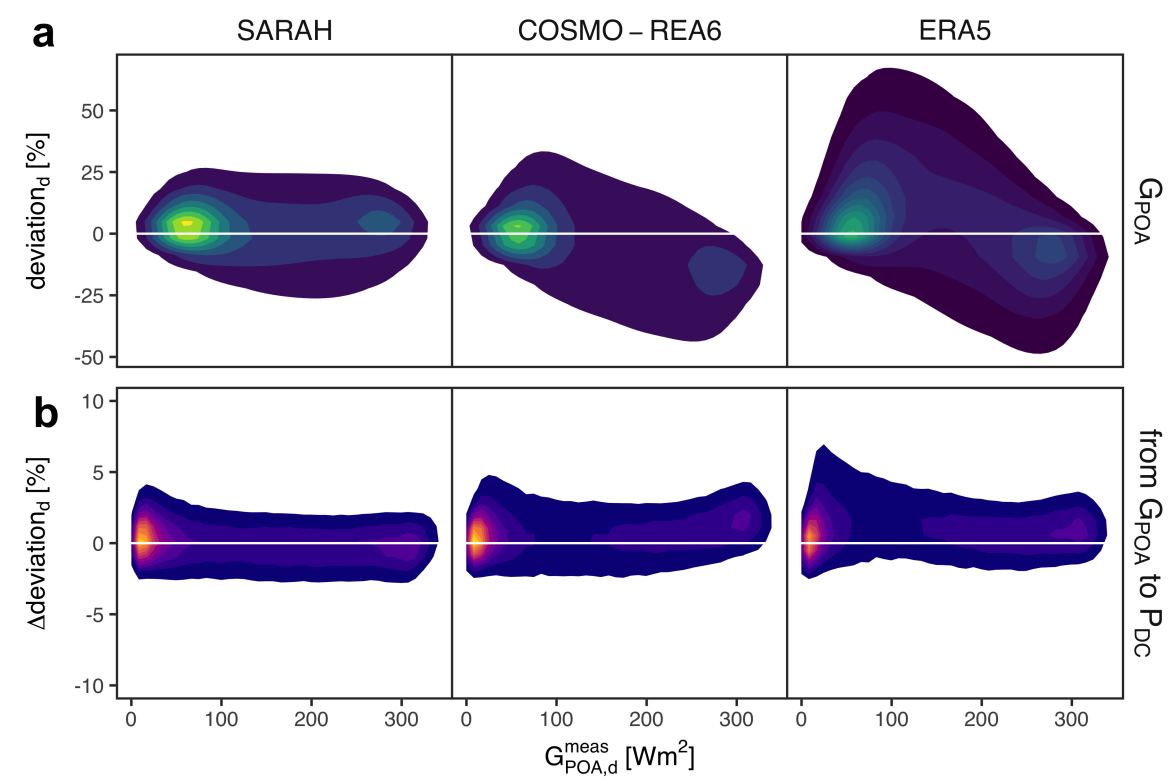

Figure 8: (a) 2D density plot of daily deviations in $G_{\mathrm{POA}}$ between simulations using radiation databases and that using station measurements against $G_{\mathrm{POA}}$. (b) $2 \mathrm{D}$ density plot of the change of daily deviations through the PV module model against $G_{\mathrm{POA}}$.

The $\Delta$ bias $_{y}$ through the PV module model can be explained by the interaction of curves shown in Fig. 7c with the distribution of daily deviations with irradiance (Fig. 8a). SARAH exhibited a negligible $\Delta{b i a s_{y}}_{y}$ in the PV module model within $\pm 0.1 \%$ because its deviations were evenly distributed with irradiance (Fig. 8a). Conversely, a positive $\Delta b i a s_{y}$ was obtained in the PV module model with both reanalyses: $+0.92 \%$ and $+0.14 \%$ for COSMO-REA6, and $+1.52 \%$ and $+0.58 \%$ for ERA5, for locations below and above $55^{\circ} \mathrm{N}$, respectively. As discussed above, this is because both products present an unbalanced error distribution showing positive deviations under cloudy conditions (low irradiance days) and negative deviations under clear 
conditions (primarily high irradiance days). Irradiance effects dominate $\eta_{\text {rel }}$ in low irradiance days, so an overestimated irradiance leads to an overestimated $\eta_{\mathrm{rel}}$, and hence to a positive $\Delta b i a s_{y}$. On the other hand, temperature effects dominate $\eta_{\text {rel }}$ in high irradiance days. Here an underestimated irradiance leads to a too low module temperature, and as a consequence, an overestimated $\eta_{\text {rel }}$ that results in a positive $\Delta b i a s_{y}$ as well. The combination of both effects results in the banana-shaped curves obtained in Fig. 8b, explaining why the bias got more positive in the PV module model. In COSMO-REA6, the positive $\Delta$ bias $_{y}$ was mostly driven by an underestimated temperature in days with high irradiance (above $250 \mathrm{~W} / \mathrm{m}^{2}$ ) due to the excess of aerosols (Fig. 8b), whereas the positive $\Delta b i a s_{y}$ of ERA5 is primarily caused by an overestimated irradiance in days with low irradiance (below $200 \mathrm{~W} / \mathrm{m}^{2}$ ) due to the underestimation of clouds (Fig. 8b). As in the transposition model, the bias was amplified through the PV module model in simulations based on reanalyses due to the intra-annual variation of their deviations with the atmospheric transmissivity.

\subsection{Propagation of the bias with different module inclination angles}

The propagation of the bias through the transposition model showed a clear dependence on the module inclination angle. The $\Delta b i a_{y}$ grew linearly with the inclination angle up to the optimum inclination at each location (Fig. 9). This trend was common to all databases and locations regardless the sign of $\Delta b i a s_{y}$, driven by the increasing contribution of beam irradiance with the inclination angle. $\Delta{b i a s_{y}}_{y}$ increased more rapidly for databases with an imbalanced estimation of beam and diffuse components, such as ERA5 in Germany (DWD-662) and COSMO-REA6 in high latitudes (FMI-4714). In general, the trend in bias continued at a smaller rate beyond the optimum angle. This may be related to the fact that for an interval above the optimum angle $B_{\mathrm{POA}}$ still increases while $D_{\mathrm{POA}}$ continues to fall. Thus, the trend in bias caused by an imbalance of $B$ and $D$ will continue.

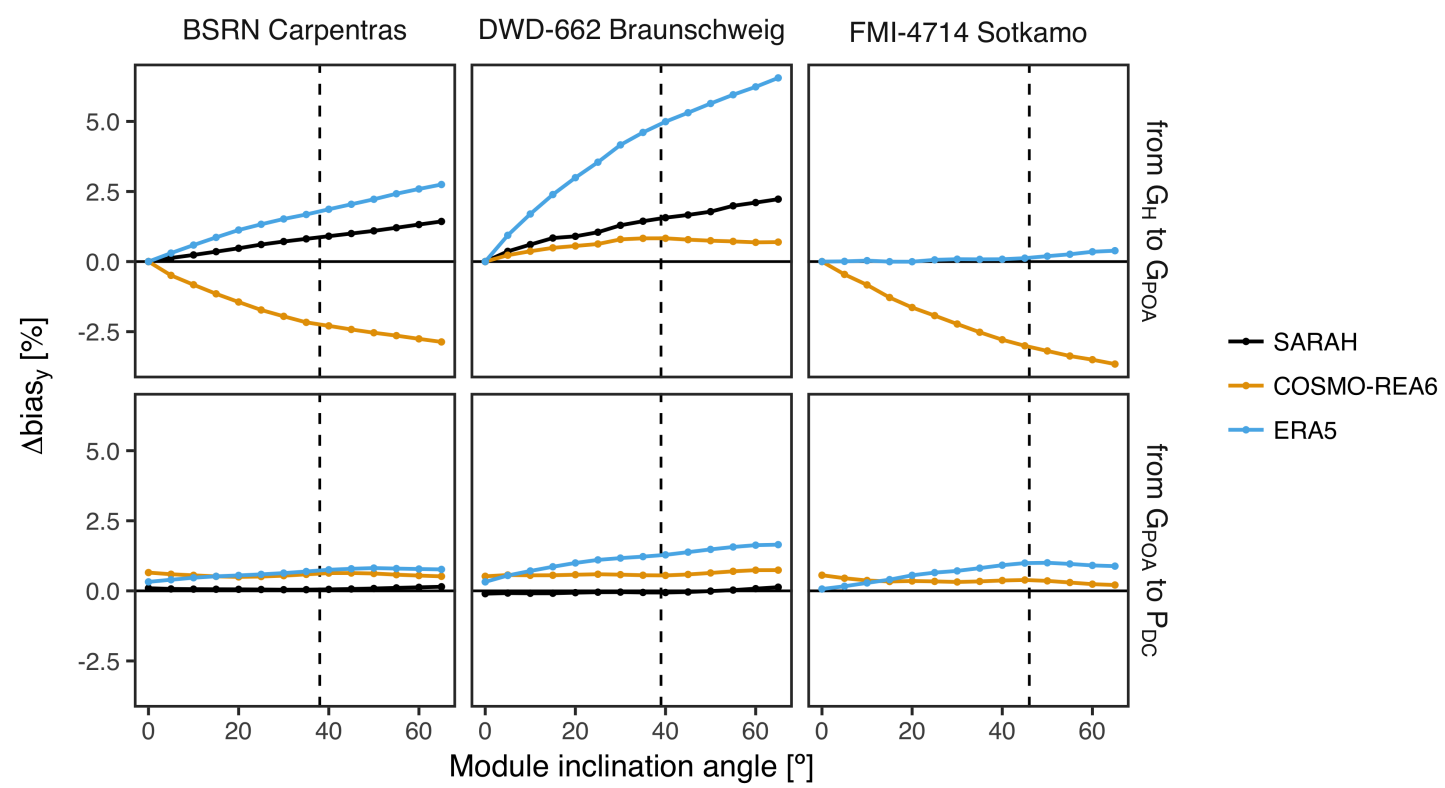

Figure 9: Influence of module inclination angle on bias propagation. The dashed line shows the optimum inclination angle at each location. 
The $\Delta$ bias $_{y}$ in the PV module model was small and virtually constant along different inclination angles because the inclination angle does not directly affect the PV module model. The changes of the bias observed were side effects of the propagation of the bias in the transposition model. A large $\Delta b i a s_{y}$ in the transposition model accentuates the defects in the radiation databases, leading to a more irregular distribution of errors in $G_{\mathrm{POA}}$. This alters the calculation of the energy conversion efficiency of the module, explaining the amplification of the bias in the PV module model.

\section{Conclusions}

PV system simulations using radiation databases (SARAH, ERA5, and COSMO-REA6) were compared against a simulation using ground measurements to analyze the propagation of the bias in $G_{H}$ through the PV modeling chain. As the rest of the parameters involved were similar between simulations, the changes in the bias observed from $G_{H}$ to $P_{\mathrm{DC}}$ may be only caused by the source of radiation data used.

Significant differences were observed between geographic areas and databases. In mid and low European latitudes, the bias of COSMO-REA6 and ERA5 substantially changed through the simulations because their deviations in $G_{H}$ varied with the atmospheric transmissivity. ERA5 especially overestimates under cloudy conditions due to an underestimation of cloud coverage, while COSMO-REA6 particularly underestimates under clear sky due to an excess of aerosols. This problem was particularly severe in ERA 5 which showed a $\Delta$ bias $_{y}$ of $+7.61 \%$ through the simulations. On the other hand, the satellite-based SARAH showed the smallest annual bias in $G_{H}$ and the most stable bias through the simulations. This confirms that SARAH is the best database to simulate PV systems in Central and South Europe.

The performance of SARAH and COSMO-REA6 changed dramatically in Northern Europe. The annual bias of both databases became more negative through the transposition model caused by an underestimation of beam irradiance $\left(\Delta\right.$ bias $_{y}=-1.46 \%$ in SARAH, $\Delta$ bias $_{y}=-2.67 \%$ in COSMO-REA6). In the case of SARAH, this may be related to the shallow satellite viewing angles and snow detection problems. Conversely, ERA5 showed the smallest $\Delta b_{i a s_{y}}$ and the best annual bias in both $G_{H}$ and $P_{\text {DC }}$. ERA5 not only complements SARAH above $65^{\circ} \mathrm{N}$ but also outperforms it between $55^{\circ} \mathrm{N}$ and $65^{\circ} \mathrm{N}$. These are promising results for using ERA5 as a complement of satellite-based databases in regions not covered by geostationary satellites such as Northern Europe. Nonetheless, ERA5 still shows large intra-annual deviations in high latitudes due to cloud-related errors, so users should keep in mind that the uncertainty of yield predictions from ERA5 in high latitudes may be larger than that from SARAH in Central Europe.

The bias in $G_{H}$ is the traditional metric for selecting radiation databases because it is the main driver of the bias in $P_{\mathrm{DC}}$. However, the bias can significantly change through the PV modeling chain due to secondary effects of uncertainties in estimated irradiance on sub-models that depend on irradiance. The greatest amplifications occurred through the transposition model ranging from $\pm 1 \%$ up to $+6 \%$. Their magnitude increased linearly with the inclination angle, and they were related to an incorrect estimation of beam and diffuse irradiance. The amplification of the bias through the PV module model was around $+1 \%$. It was caused by the effects of high intra-annual errors in $G_{H}$ on module efficiency, which depends on irradiance directly, and indirectly via module temperature. Overall, the annual bias was substantially amplified in simulations using reanalysis databases because their daily deviations vary with the atmospheric transmissivity due to an incorrect prediction of clouds. These second-order effects cannot be neglected when selecting a radiation database for PV system simulations because databases 
showing the smallest annual bias in $G_{H}$ do not always provide the least biased yield predictions. Besides, the amplification of the bias also affects energy rating studies because they alter the estimated real efficiency of the modules, and hence the performance ratio.

\section{Acknowledgements}

R. Urraca is funded by the fellowship FPI-UR-2014 granted by University of La Rioja. We would like to acknowledge the CM SAF project, the ECMWF and the HErZ/DWD for producing the radiation databases used in this study.

\section{References}

Axaopoulos, P., Fylladitakis, E., Gkarakis, K., 2014. Accuracy analysis of software for the estimation and planning of photovoltaic installations. URL: https://dx.doi.org/10.1007/s40095-014-0071-y, doi:10.1007/ s40095-014-0071-y.

Becker, R., Behrens, K., 2012. Quality assessment of heterogeneous surface radiation network data. Advances in Science \& Research 8, 93-97. URL: http://dx.doi.org/10.5194/asr-8-93-2012.

Bollmeyer, C., Keller, J., Ohlwein, C., Wahl, S., Crewell, S., Friederichs, P., Hense, A., Keune, J., Kneifel, S., Pscheidt, I., Redl, S., Steinke, S., 2015. Towards a high-resolution regional reanalysis for the European CORDEX system. Quarterly Journal of the Royal Meteorological Society 141,1-15. URL: https://dx . doi .org/10.1002/qj .2486.

BSRN, 2017. Baseline Surface Radiation Network. URL: http://bsrn. awi .de. [accessed 15.08.17].

Chen, Y., Bundy, D., Hoff, S., 1998. Modeling the variation of wind speed with height for agricultural source pollution control. Agricultural and Biosystems Engineering Publications 372. URL: https://lib.dr. iastate.edu/abe_eng_ pubs/372.

CM SAF, 2015. The Satellite Application Facility on Climate Monitoring. URL: http://www . cmsaf .eu/EN/Home/home_ node.html. [accessed 20.10.16].

Cole, I., Palmer, D., Goss, B., Gottschalg, R., 2017. Impact analysis of irradiance dataset selection on photovoltaic system energy yield modeling, in: 1st International Conference on Large-Scale Grid Integration of Renewable Energy in India, 6-8 September 2017, New Delhi, India, pp. 1-10.

Dee, D.P., Uppala, S.M., Simmons, A.J., Berrisford, P., Poli, P., Kobayashi, S., Andrae, U., Balmaseda, M.A., Balsamo, G., Bauer, P., Bechtold, P., Beljaars, A.C.M., van de Berg, L., Bidlot, J., Bormann, N., Delsol, C., Dragani, R., Fuentes, M., Geer, A.J., Haimberger, L., Healy, S.B., Hersbach, H., Hólm, E.V., Isaksen, L., Kållberg, P., Köhler, M., Matricardi, M., McNally, A.P., Monge-Sanz, B.M., Morcrette, J.J., Park, B.K., Peubey, C., de Rosnay, P., Tavolato, C., Thépaut, J.N., Vitart, F., 2011. The ERA-Interim reanalysis: configuration and performance of the data assimilation system. Quarterly Journal of the Royal Meteorological Society 137, 553-97. URL: http://dx.doi.org/10.1002/qj .828.

Dirnberger, D., Müller, B., Reise, C., 2015. PV module energy rating: opportunities and limitations. Progress in Photovoltaics 23, 1754-1770. URL: http://dx.doi.org/10.1002/pip.2618.

Dobos, A.P., 2014. PVWatts version 5 manual. NREL technical report. URL: https://www.nrel.gov/docs/fy14osti/ $62641 . \mathrm{pdf}$.

DWD, 2016. Deutscher Wetterdienst. URL: http://www.dwd.de/DE/Home/home_node.html. [accessed 10.10.16].

ECMWF, 2017. ERA5 data documentation. European Centre for Medium-range Weather Forecast (ECMWF). URL: https://software.ecmwf .int/wiki/display/CKB/ERA5+data+documentation.

Ela, E., Diakov, V., Ibanez, E., Heaney, M., 2013. Impacts of variability and uncertainty in solar photovoltaic generation at multiple timescales. NREL. URL: https://www.nrel.gov/docs/fy13osti/58274.pdf.

European Commission JRC, 2018. Pvgis: Photovoltaic Geographical Information System. URL: http://re.jrc.ec. europa.eu/pvgis.html. [accessed 15.01.18].

Faiman, D., 2008. Assessing the outdoor operating temperature of photovoltaic modules. Progress in Photovoltaics, Research and Applications 16, 307-315. URL: http://dx.doi .org/10.1002/pip.813.

FMI, 2016. Finish Meteorological Institute. URL: http://en.ilmatieteenlaitos.fi. [accessed 10.10.16].

Frank, C., Wahl, S., Keller, J., Pospichal, B., Hense, A., Crewell, S., 2018. Bias correction of a novel european reanalysis data set for solar energy applications. Solar Energy 164,12-24. URL: https://doi .org/10.1016/j . solener. 2018. 02.012 .

Frank, C., Wahl, S., Keller, J., Pospihal, B., Hense, A., Crewell, S., 2017. A novel data set for solar energy applications based on high resolution reanalysis COSMO-REA6, in: 5th International Conference on Reanalysis (ICR5), 13-17 November 2017, Rome, Italy. URL: ftp://ftp.meteo.uni-bonn.de/pub/reana/presentations/Rome2017/ radiation_bias_correction.pdf.

Freeman, J., Whitmore, J., Blair, N., Dobos, A.P., 2014. Validation of multiple tools for flat plate photovoltaic modeling against measured data. NREL technical report. URL: https ://www.nrel.gov/docs/fy14osti/61497.pdf. 
GeoModel Solar, 2018. SOLARGIS pvPlanner. URL: https://solargis.info/pvplanner/\#tl=Google:hybrid\&bm= satellite. [accessed 10.01.18].

Goss, B., Gottschalg, R., Betts, T., 2012. Uncertainty analysis of photovoltaic energy yield prediction, in: 8th Photovoltaic Science Application and Technology (PVSAT-8) Conference and Exhibition,2-4 April 2012, Newcastle, England, pp. $157-160$.

Gracia, A.M., Huld, T., 2013. Performance comparison of different models for the estimation of global irradiance on inclined surfaces. Validation of the model implemented in PVGIS. JRC Technical Report. URL: https://publications.europa.eu/en/publication-detail/-/publication/ $4 \mathrm{ef} 8 \mathrm{c} 4 \mathrm{e} 1-4397-4 \mathrm{e} 27-8487-448786327 \mathrm{f} 27$.

Gracia Amillo, A., Huld, T., Müller, R., 2014. A new database of global and direct solar radiation using the Eastern Meteosat satellite, models and validation. Remote Sensing 6, 8165-8189. URL: http;//dx.doi.org/10.3390/ rs6098165.

Gueymard, C., 2014. A review of validation methodologies and statistical performance indicators for modeled solar radiation data: Towards a better bankability of solar projects. Renewable and Sustainable Energy Reviews 39, 10241034. URL: http://dx.doi.org/10.1016/j.rser.2014.07.117.

Gueymard, C.A., Ruiz-Arias, J.A., 2016. Extensive worldwide validation and climate sensitivity analysis of direct irradiance predictions from 1-min global irradiance. Solar Energy 128, 1-30. URL: https://doi.org/10.1016/j. solener.2015.10.010.

Habte, A., Wilcox, S., Stoffel, T., 2015. Evaluation of Radiometers Deployed at the National Renewable Energy Laboratory's Solar Radiation Research Laboratory. NREL technical report, NREL/TP-5D00-60896. URL: https: //www.nrel.gov/docs/fy14osti/60896.pdf.

Hansen, C.W., Martin, C.M., 2015. Photovoltaic system modeling: uncertainty and sensitivity analyses. SANDIA Reports. URL: http://prod.sandia.gov/techlib/access-control.cgi/2015/156700.pdf.

Huld, T., Friesen, G., Skoczek, A., Kenny, R.P., Sample, T., Field, M., Dunlop, E.D., 2011. A power-rating model for crystalline silicon PV modules. Solar Energy Materials \& Solar Cells 95, 3359-3369. URL: 10.1016/j . solmat . 2011. 07.026 .

Huld, T., Gracia Amillo, A.M., 2015. Estimating PV module performance over large geographical regions: The role of irradiance, air temperature, wind speed and solar spectrum. Energies 8, 5159-5181. URL: http://dx.doi.org/10. $3390 /$ en8065159

Huld, T., Pinedo, I., 2015. Spatial downscalling of 2-meter air temperature using operational forecast data. Energies 8, 2381-2411. URL: http://dx.doi.org/10.3390/en8042381.

Huld, T., Salis, E., Pozza, A., Herrmann, W., Müllejans, H., 2016. Photovoltaic energy rating data sets for Europe. Solar Energy 133, 349-362. URL: http://dx.doi.org/10.1016/j. solener.2016.03.071.

Huld, T., Suri, M., Dunlop, E., 2008. Geographical variation of the conversion efficiency of crystalline silicon photovoltaic modules in Europe. Progress in Photovoltaics: Research and Applications 16, 595-607. URL: http: //dx.doi.org/10.1002/pip.846.

IEC, 2016. IEC 61853-2. Photovoltaic (PV) module performance testing and energy rating - Part 2: Spectral responsivity, incidence angle and module operating temperature measurements. International Electrotechnical Commission (IEC) Central Office. URL: https://webstore.iec.ch/publication/25811.

Inman, R., Pedro, H., Coimbra, C., 2013. Solar forecasting methods for renewable energy integration. Progress in Energy and Combustion Science 39, 535-576. URL: http://dx. doi .org/10.1016/j . pecs.2013.06.002.

Jäger-Waldau, A., 2017. PV status report 2017. JRC, European Commission. URL: http://publications.jrc.ec . europa.eu/repository/bitstream/JRC103426/ldna28159enn.pdf.

JCGM 100:2008, 2008. Evaluation of measurement data - guide to the expression of uncertainty in measurement. Joint Committee for Guides in Metrology (JCGM).

JCGM 104:2009, 2009. Evaluation of measurement data - An introduction to the "Guide to the expression of uncertainty in measurement" and related documents. Joint Committee for Guides in Metrology (JCGM).

Koehl, M., Heck, M., Wiesmeier, S., Wirth, J., 2011. Modeling of the nominal operating cell temperature based on outdoor weathering. Solar Energy Materials \& Solar Cells 95, 1638-1646. URL: http://dx.doi.org/10.1016/j . solmat.2011.01.020.

Long, C.N., Dutton, E.G., 2002. BSRN Global Network recommended QC tests, V2.0. BSRN Technical Report URL: http://ezksun3.ethz.ch/bsrn/admin/dokus/qualitycheck.pdf.

MACC Reanalysis, 2015. Monitoring Atmospheric Composition and Climate. URL: http://apps.ecmwf.int/ datasets/data/macc-reanalysis/levtype=sfc/.

Martin, N., Ruiz, J., 2001. Calculation of the PV modules angular losses under field conditions by means of an analytical model. Solar Energy Materials \& Solar Cells 70, 25-38. URL: http: dx . doi .org/10.1016/S0927-0248(00) 00408-6.

Müller, B., Bostock, P., Farnung, B., Reise, C., 2017. A framework to calculate uncertainties for lifetime energy yield predictions of PV systems, in: IEEE PV Specialist Conference (PVSC), 25-30 June 2017, Washington, USA, pp. 1-5.

Müller, B., Hardt, L., Armbruster, A., Kiefer, K., Reise, C., 2016. Yield predictions for photovoltaic power plants: empirical validation, recent advances and remaining uncertainties. Progress in Photovoltaics 24, 570-583. URL: http://dx.doi.org/10.1002/pip.2616. 
Müller, B., Heydenreich, W., Kiefer, K., Reise, C., 2009. More insights from the monitoring of real world PV power plants - A comparison of measured to predicted performance of PV systems, in: 24th European Photovoltaic Solar Energy Conference, 21-25 September 2009, Hamburg, Germany, pp. 3888-3892. URL: http://dx . doi .org/10.4229/ 24thEUPVSEC2009-5A0.8.1, doi:10.4229/24thEUPVSEC2009-5A0.8.1.

Müller, B., Reise, C., Heydenreich, W., Kiefer, K., 2007. Are yield certificates reliable? a comparison to monitored real world results, in: 22nd European Photovoltaic Solar Energy Conference and Exhibition, September 3-7, 2007, Milan, Italy, pp. 1-4. URL: http://dx.doi.org/10.13140/2.1.3209.4405, doi:10.13140/2.1.3209.4405.

Müller, R., Pfeifroth, U., Träger-Chatterjee, C., 2015a. Towards optimal aerosol information for the retrieval of solar surface radiation using Heliosat. Atmosphere 6, 863-878. URL: http://www.mdpi . com/2073-4433/6/7/863.

Müller, R., Pfeifroth, U., Träger-Chatterjee, C., Cremer, R., Trentmann, J., Hollmann, R., 2015b. Surface solar radiation data set - Heliosat (SARAH) - Edition 1. Satellite Application Facility on Climate Monitoring (CM SAF). URL: http://dx.doi.org/10.5676/EUM_SAF_CM/SARAH/V001, doi:10.5676/EUM_SAF_CM/SARAH/V001.

Müller, R., Pfeifroth, U., Träger-Chatterjee, C., Trentmann, J., Cremer, R., 2015c. Digging the METEOSAT treasure - 3 decades of solar surface radiation. Remote Sensing 7, 8067-101. URL: http://dx.doi.org/10.3390/rs70608067.

Muneer, T., 1990. Solar radiation model for Europe. Building Services Engineering Research \& Technology 4, 153-163. URL: http://dx.doi.org/10.1177/014362449001100405.

NREL, 2018. PVWatts Calculator. URL: http://pvwatts.nrel.gov. [accessed 10.01.18].

Pfeifroth, U., Kothe, S., Trentmann, J., 2016. Meteosat solar surface radiation and effective cloud Albedo climate data record, SARAH-2. Validation report. CM SAF, EUMETSAT Satellite Application Facility on Climate Monitoring.

Polo, J., Wilbert, S., Ruiz-Arias, J.A., Meyer, R., Gueymard, C., Súri, M., Martín, L., Mieslinger, T., Blanc, P., Grant, I., Boland, J., Ineichen, P., Remund, J., Escobar, R., Troccoli, A., Sengupta, M., Nielsen, K.P., Renne, D., Geuder, N., Cebecauer, T., 2016. Preliminary survey on site-adaptation techniques for satellite-derived and reanalysis solar radiation datasets. Solar Energy 132, 25-37. URL: http://dx. doi .org/10.1016/j . solener. 2016.03.001.

Reda, I., 2012. Method to Calculate Uncertainties in Measuring Shortwave Solar Irradiance Using Thermopile and Semiconductor Solar Radiometers. NREL technical report, NREL/TP-3B10-52194. URL: https://www.nrel.gov/ docs/fy11osti/52194.pdf.

Richter, M., De Brabandere, K., Kalisch, J., Schmidt, T., Lorenz, E., 2015. Best Practice Guide On Uncertainty in PV Modelling. 3E - University of Oldenburg. URL: http://www.perfplus.eu/frontend/files/userfiles/files/ 308991_PerfPlus_Deliverable_D2_4_20150205.pdf.

Roberts, J.J., Mendiburu Zevallos, A.A., Marotta, C., 2017. Assessment of photovoltaic performance models for system simulation. Renewable and Sustainable Energy Reviews 72, 1104-1123. URL: http://dx.doi.org/10.1016/j. rser.2016.10.022.

Sengupta, M., Habte, A., Gueymard, C., Wilbert, S., Renné, D., 2017. Best practices handbook for the collection and use of solar resource data for solar energy applications: Second edition. NREL technical report, NREL/TP-5D00-68886. URL: https://www.nrel.gov/docs/fy18osti/68886.pdf.

Thevenard, D., Pelland, S., 2013. Estimating the uncertainty in long-term photovoltaic yield predictions. Solar Energy 91, 432-445. URL: http://dx.doi.org/10.1016/j. solener.2011.05.006.

Urraca, R., Gracia Amillo, A., Huld, T., Martinez-de Pison, F.J., Trentmann, J., Lindfors, A., Riihelä, A., Sanz Garcia, A., 2017a. Quality control of solar radiation data with satellite-based products. Solar Energy 158, 49-62. URL: http://dx.doi.org/10.1016/j.solener.2017.09.032.

Urraca, R., Gracia-Amillo, A., Koubli, E., Huld, T., Trentmann, J., Riihelä, A., Lindfors, A., Palmer, D., Gottschalg, R., Antonanzas-Torres, F., 2017b. Extensive validation of CM SAF surface radiation products over Europe. Remote Sensing of Environment 199, 171-186. URL: https://dx.doi.org/10.1016/j.rse.2017.07.013.

Urraca, R., Huld, T., Gracia-Amillo, A., Martinez-de Pison, F.J., Kaspar, F., A., S.G., 2018a. Evaluation of global horizontal irradiance estimates from ERA5 and COSMO-REA6 reanalyses using ground and satellite-based data. Solar Energy 164, 339-354. URL: https://dx.doir.org/10.1016/j. solener.2018.02.059.

Urraca, R., Huld, T., Martinez-de Pison, F., Sanz-Garcia, A., 2018b. Sources of uncertainty in annual global horizontal solar radiation data. Solar Energy 170, 873-884. URL: https://doi .org/10.1016/j.solener.2018.06.005.

Urraca, R., Martinez-de Pison, E., Sanz-Garcia, A., Antonanzas, J., Antonanzas-Torres, F., 2017c. Estimation methods for global solar radiation: Case study evaluation of different approaches in central Spain. Renewable \& Sustainable Energy Reviews 77, 1098-1113. URL: http://dx.doi.org/10.1016/j.rser.2016.11.222.

Valentin Software, 2018. Pv*sol. URL: http://pvsol-online .valentin-software.com/\#/. [accessed 10.01.18].

Ves, H., 2013. Energy yield assessment of the photovoltaic power plant. GeoModel Solar.

Vuilleumier, L., Hauser, M., Félix, C., Vignola, F., Blanc, P., Kazantzidis, A., Calpini, B., 2014. Accuracy of ground surface broadband shortwave radiation monitoring. Journal of Geophysical Research: Atmosphere , 838-860URL: http://dx.doi.org/10.1002/2014JD022335. 


\section{Appendix A. Weather stations}

Table A1: List of weather stations and years of data used in the study.

\begin{tabular}{|c|c|c|c|c|c|c|}
\hline Network & ID & Location & Longitude $\left[{ }^{\circ}\right]$ & Latitude $\left[{ }^{\circ}\right]$ & Altitude $[\mathrm{m}]$ & Years \\
\hline BSRN & CAB & Cabauw & 4.93 & 51.97 & 0 & $10-15$ \\
\hline BSRN & CAR & Carpentras & 5.06 & 44.08 & 100 & $10-15$ \\
\hline BSRN & CNR & Cener & -1.60 & 42.82 & 471 & $10-15$ \\
\hline BSRN & PAL & Palaiseau & 2.21 & 48.71 & 156 & $10-15$ \\
\hline BSRN & PAY & Payerne & 6.94 & 46.81 & 491 & 10 \\
\hline BSRN & TOR & Toravere & 26.46 & 58.25 & 70 & $10-15$ \\
\hline DWD & 183 & Arkona & 13.43 & 54.68 & 42 & $10-15$ \\
\hline DWD & 662 & Braunschweig & 10.45 & 52.29 & 81 & $10-15$ \\
\hline DWD & 691 & Bremen & 8.80 & 53.05 & 4 & $10-15$ \\
\hline DWD & 853 & Chemnitz & 12.87 & 50.79 & 418 & $10-15$ \\
\hline DWD & 1048 & Dresden-Klotzsche & 13.75 & 51.13 & 227 & $10-15$ \\
\hline DWD & 1358 & Fichtelberg & 12.95 & 50.43 & 1213 & $10-15$ \\
\hline DWD & 1684 & Görlitz & 14.95 & 51.16 & 238 & $10-15$ \\
\hline DWD & 1975 & Hamburg-Fuhlsbüttel & 9.99 & 53.63 & 11 & $10-15$ \\
\hline DWD & 2290 & Hohenpei_enberg & 11.01 & 47.80 & 977 & $10-15$ \\
\hline DWD & 2712 & Konstanz & 9.19 & 47.68 & 443 & $10-15$ \\
\hline DWD & 2928 & Leipzig-Holzhausen & 12.45 & 51.32 & 138 & $14-15$ \\
\hline DWD & 3015 & Lindenberg & 14.12 & 52.21 & 98 & $10-15$ \\
\hline DWD & 3631 & Norderney & 7.15 & 53.71 & 11 & $10-15$ \\
\hline DWD & 3668 & Nürnberg & 11.05 & 49.50 & 314 & $10-15$ \\
\hline DWD & 3987 & Potsdam & 13.06 & 52.38 & 81 & $10-15$ \\
\hline DWD & 4271 & Rostock-Warnemünde & 12.08 & 54.18 & 4 & $10-15$ \\
\hline DWD & 4336 & Saarbrücken-Ensheim & 7.11 & 49.21 & 320 & $10-15$ \\
\hline DWD & 4393 & Sankt Peter-Ording & 8.60 & 54.33 & 5 & 15 \\
\hline DWD & 4466 & Schleswig & 9.55 & 54.53 & 43 & $10-15$ \\
\hline DWD & 4642 & Seehausen & 11.73 & 52.89 & 21 & $10-15$ \\
\hline DWD & 4928 & Stuttgart (Schnarrenberg) & 9.20 & 48.83 & 314 & $10-15$ \\
\hline DWD & 5100 & Trier-Petrisberg & 6.66 & 49.75 & 265 & $10-15$ \\
\hline DWD & 5404 & Weihenstephan-Dürnast & 11.69 & 48.40 & 477 & $10-11,13-15$ \\
\hline DWD & 5705 & Würzburg & 9.96 & 49.77 & 268 & $10-15$ \\
\hline DWD & 5856 & Fürstenzell & 13.35 & 48.55 & 476 & $10-15$ \\
\hline FMI & 2 & Utö & 21.37 & 59.78 & 9 & $10-15$ \\
\hline FMI & 301 & Helsinki-Vantaa & 24.96 & 60.33 & 51 & $10-15$ \\
\hline FMI & 339 & Helsinki-Kumpula & 24.96 & 60.20 & 24 & 10,15 \\
\hline FMI & 1201 & Jokioinen & 23.50 & 60.81 & 104 & $10-15$ \\
\hline FMI & 2401 & Jyväskylä & 25.68 & 62.40 & 139 & $10-15$ \\
\hline FMI & 4714 & Sotkamo & 28.34 & 64.11 & 161 & $13-15$ \\
\hline FMI & 7501 & Sodankylä & 26.63 & 67.37 & 179 & $10-15$ \\
\hline FMI & 9603 & Utsjoki & 27.01 & 69.76 & 107 & $13-15$ \\
\hline
\end{tabular}

\section{Appendix B. Uncertainty of the reference simulation}

The uncertainty of the reference simulation is smaller in horizontal irradiance variables $\left(G_{H}\right.$, $\left.B_{H}, D_{H}\right)$, which are measurements, than in $G_{\mathrm{POA}}$ and $P_{\mathrm{DC}}$, which include the uncertainty of measured irradiance plus that of simulation models. This uncertainty can be reduced by using $G_{\mathrm{POA}}$ and $P_{\mathrm{DC}}$ measurements as well, which is the common approach for validating PV simulation models, but those are available only at a few sites. On the contrary, our goal is to analyze the suitability of radiation databases for simulating PV systems. Thus, having a spatially uniform group of weather stations to feed simulations and evaluate radiation databases across 
Europe was more important than having high-quality but sparsely distributed $G_{\mathrm{POA}}$ and $P_{\mathrm{DC}}$ measurements.

The uncertainty analysis was made following the Guide to the Expression of Uncertainty in Measurement (GUM) (JCGM 100:2008, 2008; JCGM 104:2009, 2009), using the expanded uncertainty $(u)$ with a $95 \%$ confidence level (coverage factor of 1.96 for normally distributed variables). The uncertainty of annual values was analyzed because this is the temporal resolution used to calculate the uncertainty of yield predictions (Thevenard and Pelland, 2013; Huld and Gracia Amillo, 2015; Müller et al., 2016). Annual uncertainties were estimated from values reported by previous studies applying the uncertainty propagation rules, due to the lack of high-quality collocated data to calculate $u$ statistically.

The uncertainty of measured variables $\left(G_{H}, D_{H}\right)$ depends on the quality of the sensor and the operating conditions at the stations. In the present study, most stations use secondary standard pyranometers (shaded and unshaded), which have a typical uncertainty of $\pm 3 \%$ and $\pm 2 \%$ for hourly and daily values, respectively (Sengupta et al., 2017). These values do not include additional uncertainties due to calibration and operational defects. However, the presence of significant operational errors in the weather stations used is unlikely. All stations are maintained by organizations that implement strict measuring protocols. For instance, BSRN follows the most stringent guidelines among all the networks used and has an accuracy target of $2 \%$ for $G_{H}$ and $D_{H}$ (1-min values) (Vuilleumier et al., 2014). Besides, all measurements have passed the BSRN QC tests and a QC procedure based on the analysis of the stability of deviations between measurements and satellite-based estimations (Urraca et al., 2017a). This second method was able to detect operational errors and some equipment errors related to sensor miscalibrations at several European (Urraca et al., 2017b) and Spanish (Urraca et al., 2018b) stations, but it did not find any defect in the current group of weather stations.

Based on this, we assumed an uncertainty in annual $G_{H}$ and $D_{H}$ of $\pm 2 \%$ and $\pm 3.5 \%$ for stations below and above $55^{\circ} \mathrm{N}$, respectively. The uncertainty of annual values is lower than that of daily values due to the compensation of seasonal deviations. We assumed a higher uncertainty at high-latitude stations because the difficult measuring conditions, such as the high frequency of hours with low solar elevation angles, aggravate the equipment errors of pyranometers. These values are rough estimates just for the analysis of uncertainty propagation through the simulations. A more detailed analysis, such as those made by Reda (2012), Vuilleumier et al. (2014), or Habte et al. (2015), would require the evaluation of the particular conditions of the stations such as the specific pyranometer model used, dates of sensor replacement and re-calibrations. Besides, uncertainty also varies spatially with latitude and temporally from season to season due to changes in the incoming irradiance and solar elevation angles (Habte et al., 2015). Uncertainty fluctuations due to changes in either equipment or operating conditions are more likely at FMI or DWD than at BSRN. A couple of DWD stations were temporally equipped with SCAPP sensors, which simultaneously measure $B_{N}$ and $D_{H}$ using a silicon detector. The uncertainty of SCAPP measurements is higher due to the limited spectral response of silicon, among other issues. Besides, the uncertainty in $D_{H}$ is not homogeneous between FMI stations due to variations in the equipment (sorted by increasing accuracy): (i) shading ring (up to 2012), (ii) Delta-T SPN1 multipyranometer (2012-), (iii) shading ball on solar tracker.

The uncertainty increases for $B_{H}$, because this variable was calculated as the difference between $G_{H}$ and $D_{H}$. In sums and differences, absolute uncertainties $(U)$ add in quadrature,

$$
y=x_{1} \pm x_{2} \quad \rightarrow \quad U(y)=\sqrt{\left.U^{2}\left(x_{1}\right)+U^{2}\left(x_{2}\right)\right)},
$$

so the uncertainty in $B_{H}$ is estimated as 


$$
U\left(B_{H}\right)=\sqrt{U^{2}\left(G_{H}\right)+U^{2}\left(D_{H}\right)} .
$$

Absolute uncertainties $(U)$ were transformed into relative ones $(u)$ by using the annual averages for all stations below $55^{\circ} \mathrm{N}\left(\overline{G_{H}}=130 \mathrm{~W} / \mathrm{m}^{2}, \overline{B_{H}}=66 \mathrm{~W} / \mathrm{m}^{2}, \overline{D_{H}}=64 \mathrm{~W} / \mathrm{m}^{2}\right)$ and for all stations above $55^{\circ} \mathrm{N}\left(\overline{G_{H}}=104 \mathrm{~W} / \mathrm{m}^{2}, \overline{B_{H}}=56 \mathrm{~W} / \mathrm{m}^{2}, \overline{D_{H}}=48 \mathrm{~W} / \mathrm{m}^{2}\right)$.

The uncertainty propagation through simulations was estimated assuming that the PV simulation model is a series of multiplicative factors that transform incoming irradiance into $P_{\mathrm{DC}}$ (Thevenard and Pelland, 2013). The only part of the modeling chain that is not strictly a multiplicative factor is the transposition model, but it is usually treated as if it were. In multiplications, relative uncertainties add in quadrature,

$$
y=A \cdot x_{1} \times B \cdot x_{2} \rightarrow u(y)=\sqrt{u^{2}\left(x_{1}\right)+u^{2}\left(x_{2}\right)},
$$

so the uncertainty in $G_{\mathrm{POA}}$ and $P_{\mathrm{DC}}$ is

$$
\begin{aligned}
u\left(G_{\mathrm{POA}}\right) & =\sqrt{u^{2}\left(B_{H}\right)+u^{2}(\text { trans.model })} \\
u\left(P_{\mathrm{DC}}\right) & =\sqrt{u^{2}\left(B_{H}\right)+u^{2}(\text { trans.model })+\mathrm{u}^{2}(\text { PVmod.model }) .}
\end{aligned}
$$

$u\left(B_{H}\right)$ was considered the initial uncertainty for the transposition model because $B_{H}$ had the largest uncertainty among the three horizontal irradiance variables. An annual uncertainty of $3 \%$ was assumed for both transposition and PV module models based on the studies made by Müller et al. (2016) and Thevenard and Pelland (2013).

$$
\begin{aligned}
& \begin{array}{l}
\text { a } u\left(B_{\mathrm{H}}\right)=4.4 \% \quad u\left(G_{\mathrm{POA}}\right)=5.3 \% \\
\begin{array}{l}
u\left(G_{\mathrm{H}}\right) \\
u\left(D_{\mathrm{H}}\right)=2 \%
\end{array}-\text { Difference }
\end{array} \\
& \begin{array}{l}
\text { b } u\left(B_{\mathrm{H}}\right)=7.2 \% \quad u\left(G_{\mathrm{POA}}\right)=7.8 \% \\
\begin{array}{l}
u\left(G_{\mathrm{H}}\right)=3.5 \% \\
u\left(D_{\mathrm{H}}\right)=3.5 \%
\end{array}-\text { Difference } \quad \begin{array}{c}
\text { Transposition model } \\
(3 \%)
\end{array} \\
\begin{array}{l}
\text { PV module model } \\
(3 \%)
\end{array}-u\left(P_{\mathrm{DC}}\right)=8.3 \%
\end{array}
\end{aligned}
$$

Figure B.1: Estimated annual uncertainty in the reference simulation (a) below $55^{\circ} \mathrm{N}$ and (b) above $55^{\circ} \mathrm{N}$. 